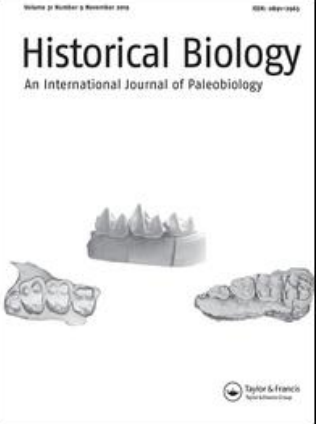

Historical Biology

An International Journal of Paleobiology

ISSN: (Print) (Online) Journal homepage: https://www.tandfonline.com/loi/ghbi20

\title{
A new phylogeny of cerapodan dinosaurs
}

\section{P. -E. Dieudonné , P. Cruzado-Caballero , P. Godefroit \& T. Tortosa}

To cite this article: P. -E. Dieudonné , P. Cruzado-Caballero, P. Godefroit \& T. Tortosa (2020): A new phylogeny of cerapodan dinosaurs, Historical Biology, DOI: 10.1080/08912963.2020.1793979

To link to this article: https://doi.org/10.1080/08912963.2020.1793979

曲 Published online: 20 Jul 2020.

Submit your article to this journal

Q View related articles $₫$

View Crossmark data \lceil 


\title{
A new phylogeny of cerapodan dinosaurs
}

\author{
P. -E. Dieudonné $(\mathbb{D})^{a, b}$, P. Cruzado-Caballero $\mathbb{D}^{\mathrm{a}, \mathrm{b}, \mathrm{c}}, \mathrm{P}$. Godefroit ${ }^{\mathrm{d}}$ and T. Tortosa ${ }^{\mathrm{e}}$
}

aInstituto de Investigación en Paleobiología y Geología (IIPG), CONICET, General Roca, Argentina; bUniversidad Nacional de Río Negro-IIPG, General Roca, Argentina; 'Grupo Aragosaurus-IUCA, Departamento de Ciencias de la Tierra, Área de Paleontología, Universidad de Zaragoza, Zaragoza, Spain;

'Directorate 'Earth and History of Life', Royal Belgian Institute of Natural Sciences, Brussels, Belgium; 'Département des Bouches-du-Rhônee, Réserve Naturelle de Sainte-Victoire, Direction de l'Environnement, des Grands-Projets et de la Recherche, Marseille, France

\begin{abstract}
This work attempts at providing a revised framework for ornithischian phylogeny, based on an exhaustive data compilation of already published analyses, a critical re-evaluation of osteological characters and an indepth checking of characters scoring to fix mistakes that have accumulated in previous analyses; we have also included recently described basal ornithischians, marginocephalians and ornithopods. 'Heterodontosaurids' are recovered as a paraphyletic group of basal Marginocephalia that progressively lead to the dome-headed 'true' pachycephalosaurs. 'Heterodontosaurids' consequently fall within Pachycephalosauria sensu Sereno, 1998. The reconfiguration of basal cerapodan relationships pulls the origins of ornithopods to the earliest stages of the Jurassic. Based on the present analysis, we also discuss ornithopod relationships, with a particular focus on basal Iguanodontia. Tenontosaurus is found as the basalmost iguanodontian. The monophyly of Rhabdodontomorpha in a position more derived than Tenontosaurus is supported by the present analysis.
\end{abstract}

\section{ARTICLE HISTORY}

Received 8 March 2020

Accepted 6 July 2020

\section{KEYWORDS}

Phylogeny; Cerapoda;

Marginocephalia;

Pachycephalosauria;

Ornithopoda; basal

iguanodontia

\section{Introduction}

On the basis of fundamental differences in their pelvic structure, Seeley (1887) divided Dinosauria into two suborders: Saurischia and Ornithischia. The ornithischian pelvis is 'opisthopubic', meaning that the pubis points ventrally and posteriorly parallel with the ischium. Additionally, the ilium has an anteriorly pointing preacetabular process, so that the pelvis appears four-pronged in lateral view. Basal ornithischians are poorly documented by scarce fossils; consequently, their origin and phylogenetic relationships with saurischians and silesaurids have long been, and are still discussed (Galton 1970; Bakker and Galton 1974; Gauthier 1986; Langer and Benton 2006; Langer and Ferigolo 2013; Padian 2013; Baron et al. 2017; Baron et al. 2017; Baron and Barrett 2017). Researches dating back from the very first numerical phylogenetic analyses profoundly changed our conception of ornithischian relationships. They notably found that cursorial and sabre-toothed ornithischians - namely the Heterodontosauridae - shared synapomorphies with ornithopods, pachycephalosaurs and ceratopsians (Santa Luca 1980; Cooper 1985; Sereno 1986; Sues and Norman 1990). After Sereno (1986) created the suborder Marginocephalia to group both Ceratopsia and Pachycephalosauria, and Heterodontosauridae was placed within basal Ornithopoda (see also Cooper 1985; Salgado et al. 1997; Calvo et al. 2007). Norman et al. (2004) found heterodontosaurids at an unresolved place at the base of Cerapoda, one of their two Most Parsimonious Trees (MPTs) placed them as either basal ornithopods, whereas the other placed them as the sister group of Marginocephalia. This latter phylogenetic position for heterodontosaurids was also recovered by Xu et al. (2006). Butler et al. (2008) were the first to include an exhaustive set of ornithischians in their data matrix, and notably recovered heterodontosaurids as the basalmost, non-genasaurian ornithischians. Their data matrix was subsequently regarded as the reference point for most subsequent authors (e.g. Han et al. 2012; Padian 2013; Godefroit et al. 2014; Agnolín and Rozadilla 2017; Baron et al. 2017). Butler et al. (2008, p. 23) claimed that 'resolving the position of heterodontosaurids within Ornithischia is one of the most important tasks facing ornithischian phylogeneticists and future work should aim to combine the data set provided here with that of $\mathrm{Xu}$ et al. (2006)'. Although accurate positioning of heterodontosaurids is particularly important for polarising the character acquisition sequence at the base of Ornithischia and therefore for disentangling ornithischian origin (Agnolín and Rozadilla 2017), nobody attempted to combine both data sets so far.

During the last decade, new phylogenies of basal ornithischians have been proposed, mainly at the occasion of new taxonomic descriptions. However, those analyses were often conducted on the basis of reduced taxonomic data sets focusing on the newly described taxa (e.g. Sereno 2012; Brown et al. 2013; Rozadilla et al. 2016), and rarely reached a global consensus whenever using a more exhaustive taxonomic sampling (Godefroit et al. 2014; Boyd 2015; Herne et al. 2019; Cruzado-Caballero et al. 2019; Bell et al. 2019). As a result, the interrelationships between basal forms remain poorly resolved and/ or supported. Although Marginocephalia and Ornithopoda were among the most successful and diversified dinosaurs, especially during the Cretaceous, those clades are paradoxically weakly supported, and their origins and early diversifications are consequently poorly understood (Sereno 1986, 2000; Sues and Norman 1990; Weishampel and Heinrich 1992; Xu et al. 2006; Butler et al. 2008; Boyd 2015; Bell et al. 2019). Moreover, the recent discovery of the primitive ornithischian Laquintasaura venezuelae (Barrett et al. 2014) and the notable reinterpretation of Chilesaurus diegosuarezi as the basalmost ornithischian (Baron and Barrett 2017) continue to raise important questions about the origin of ornithischians (Baron et al. 2017; Langer et al. 2017). 
It is of course very likely that important fossil record lacunae, inadequate revisions of character scoring and homoplasies related to graviportality or quadrupedy (e.g. Dodson 1980; Winkler et al. 1997; Dieudonné et al. 2016) all partly explain difficulties in resolving the ornithischian phylogeny. The long-branch attraction phenomenon is another potential 'usual suspect' perturbating the adequacy of phylogenies. It occurs when longer branches - corresponding to better-scored taxa - are erroneously clustered together because they share more characters in common than with other taxa for which those characters are partly or wholly missing (Felsenstein 1978, 2004). Inaccurate taxon-grouping especially occurs whenever missing characters or missing taxa within the tree are non-randomly distributed (Weishampel and Heinrich 1992; Wiens 2005). For a long time, researches on ornithopods and marginocephalians focused on larger derived taxa, which are usually better preserved and easier to find in the field. The skeletons of smaller ornithischians are usually under-represented in museum collections as they are more easily destroyed during diagenetic processes and therefore more difficult to find. Data sets are consequently biased, as smaller basal taxa tend to be scored for a smaller amount of characters in comparison to larger ones (Weishampel and Heinrich 1992). Fortunately, numerous smaller ornithischian taxa have been described during the past decade (e.g. Pol et al. 2011; Zheng et al. 2012; Ösi et al. 2012; RuizOmeñaca et al. 2012; Godefroit et al. 2014; Dieudonné et al. 2016; Baron and Barrett 2017; Bell et al. 2018; Madzia et al. 2018; Herne et al. 2018, 2019), and their detailed study will certainly allow to partially get rid of the long-branch attraction problem in the future.

The present paper proposes a new phylogeny of ornithischian dinosaurs and set out new hypotheses about early cerapodan and basal iguanodontian origins based on an exhaustive data compilation of already published analyses, a critical re-evaluation of osteological charactersand an in-depth checking of characters scoring to fix mistakes that have accumulated in previous analyses. We include recently described basal ornithischians, marginocephalians and ornithopods.

Institutional abbreviations: CPBA-V: Cátedra de Paleontología de la Facultad de Ciencias Exactas de la Universidad de Buenos Aires, Argentina (Colección de vertebrados); MDS: Museo de Dinosaurios de Salas de los Infantes, Burgos Province, Spain; QM, Queensland Museum of Brisbane, Queensland, Australia.

\section{Material and methods}

This work is built on a revised version of the Dieudonné et al. (2016) data set (see character list and excel data matrix in Supplemental material 1 and 2, respectively), which already considered the data matrices from Butler et al. (2008, in its more recent version used by Ösi et al. 2012), Mcdonald et al. (2010), Brown et al. (2013) and Boyd (2015). Character scorings were here thoroughly and exhaustively revised for each taxon based on a strict bibliographic revision and, when possible, on firsthand observations (see Supplemental materials 3.1 and 3.2). For the first time, we also integrated Xu et al.'s (2006) dataset as already proposed by Butler et al. (2008). We also took into consideration improvements, criticisms, modifications and in some instances a few character scoring proposed by Cambiaso (2007), Pol et al. (2011), Gasca et al. (2014), Baron et al. (2016), Rozadilla et al. (2016, 2019), Han et al. (2018), Andrzejewski et al. (2019) and Bell et al. (2019). Thirty-six new characters were created (see Supplemental materials 1 and 2). We reintegrate 12 taxa which were previously coded by Butler et al. (2008) or by the subsequent versions of these datasets but that were excluded in Dieudonné et al.'s
(2016) dataset: Laquintasaura venezuelae, Ankylosauria, Stegosauria, Isaberrysaura mollensis, Kulindadromeus zabaikalicus, Stenopelix valdensis, Chaoyangsaurus youngi, Liaoceratops yanzigouensis, Archaeoceratops oshimai, Wannanosaurus yansiensis, Goyocephale lattimorei, Homalocephale calathocercos. We also add twelve taxa for the first time to this data-set: Camptosaurus aphanoecetes, Chilesaurus diegosuarezi, Convolosaurus marri, Eousdryosaurus nanohallucis, Kangnasaurus coetzeei, Mahuidacursor lipanglef, Morrosaurus antarcticus, Pachycephalosaurus wyomingensis, Prenocephale prenes, Stegoceras validum, Thescelosaurus assiniboiensis and Valdosaurus canaliculatus. Psittacosauridae was also recoded and split as Psittacosaurus major and Psittacosaurus mongoliensis. Dryosaurus altus was renamed 'Dryosaurus' because it was actually based on specimens that are now attributed to D. altus, Dryosaurus cf. altus and D. elderae (Carpenter and Lamanna 2015; Carpenter and Galton 2018). Following Baron et al. (2016), we regarded Stormbergia dangershoeki as synonymous to Lesothosaurus diagnosticus and coded the latter taxon accordingly. Pisanosaurus mertii was successively regarded as a non-dinosaurian dinosauriform by Agnolín and Rozadilla (2017) but as a basal ornithischian by Baron et al. (2017) and Langer et al. (2017). It was temporarily omitted from this analysis. Herrerasaurus ischigualastensis was used as the outgroup taxon.

Character \#110 (Ösi et al. 2012 \#78) and \#282 (Ösi et al. 2012 $\# 194$ and \#195) were newly treated as ordered, in addition to the already ordered characters \#150 and \#203 (from Ösi et al. 2012 \#228 and \#137, respectively). Characters \#190, \#202, \#270, \#273 (from Mcdonald et al. 2010 \#87 and \#113; Ösi et al. 2012 \#135 and \#174) were turned to unordered. The phylogenetic analysis was run under equally weighted maximum parsimony using TNT (Tree Analysis using New Technology, Goloboff et al. 2008) in its latest version (Goloboff and Catalano 2016). A heuristic search of 1000 replications of Wagner trees (with random addition sequence) was performed, followed by a Tree Bisection Reconnection branch-swapping algorithm (TBR, holding 10 trees per replicate). 2000 parsimonious trees were hold in memory. We ran a second round of TBR branch-swapping over the latter trees to optimise the total number of MPTs. Yandusaurus hongheensis was found to switch inside and outside Ornithopoda. It was pruned a posteriori while looking for the strict consensus tree. Indices of branch support (Bootstrap indices $\geq 50 \%$ and Bremer supports) were also obtained through TNT and plotted over the resulting tree (Figures 1,2). A table was built to show the phylogenetic definitions of each clade recovered in our analysis, and the characters that support them (Supplemental material 5).

We performed three templeton tests in TNT (Templeton 1983) with the TNT script developed by Alexander N. SchmidtLebuhn (2016) and tested for three alternative phylogenetic hypotheses with respect to our reference tree (Supplemental material 6, see below). The first hypothesis tests for an arbitrary positioning of Heterodontosauridae as the closest monophyletic sister group of Genasauria, according to the current assumptions about their phylogenetic relationships (Butler et al. 2008; Barrett et al. 2014; Agnolín and Rozadilla 2017). The second hypothesis tests for the positioning of Rhabdodontormopha at the base of Ankylopollexia, and the third one tests for a splitting of Rhabdodontormopha consistent with the hypotheses of Bell et al. (2019) and Madzia et al. (2020), with Muttaburrasaurus langdoni and Fostoria dhimbangunmal set within a monophyletic sister group of Ankylopollexia, and Rhabdodontidae left in the same positioning as in the strict consensus (see Supplemental Material 6 for details on the results). 


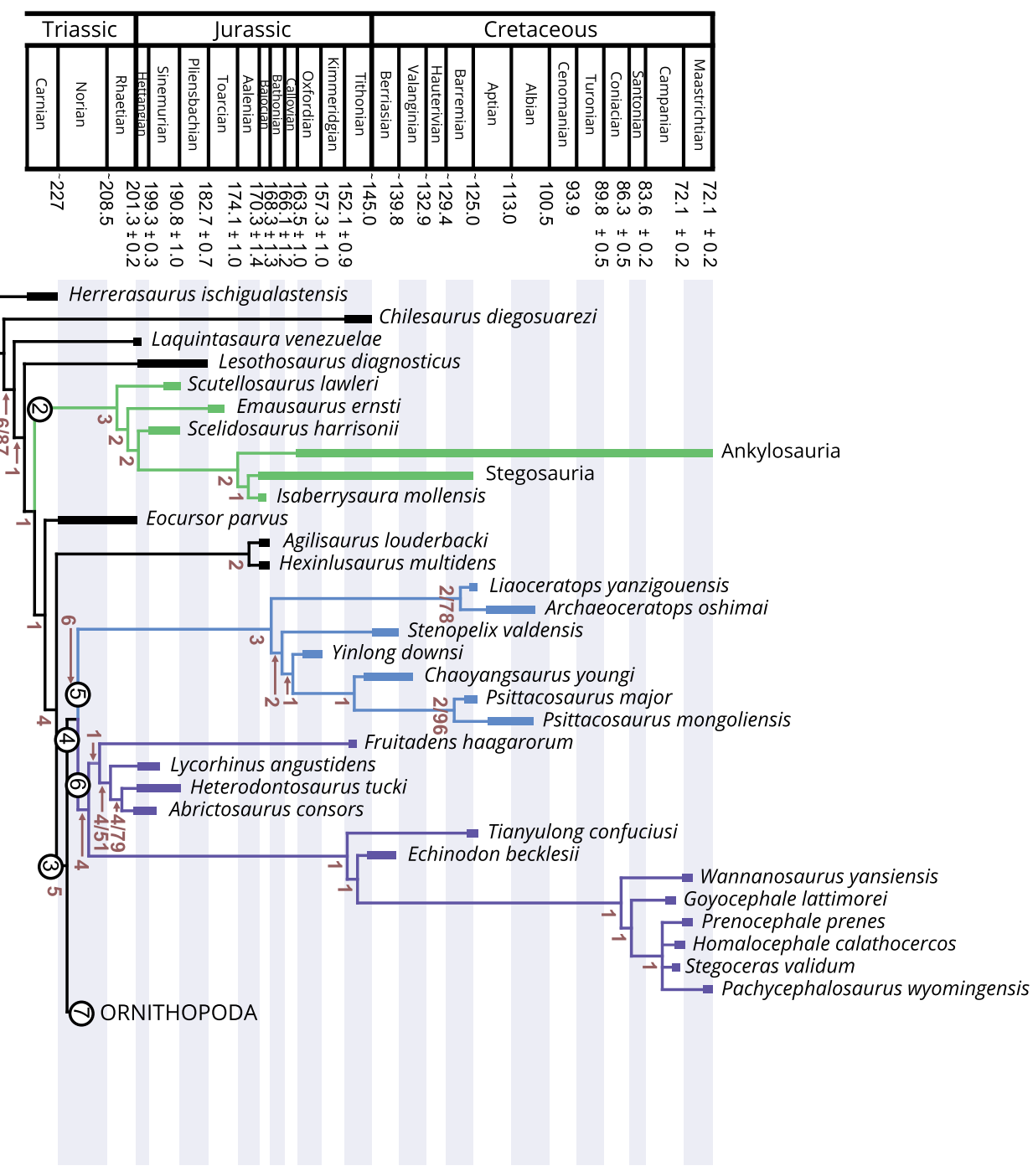

Figure 1. Strict consensus tree calibrated over the chronostratigraphic timescale of Cohen et al. (2013, updated version), showing relationships among non-ornithopodan ornithischians. The analysis was run under equally-weighted parsimony with the a posteriori removal of Yandusaurus hongheensis. Bremer supports are reported below each node. Bootstrap values are also added to the right of the Bremer indices whenever those are superior to $50 \%$. Specific clades are shown with a circled number, and some of them are highlighted using a specific colour: Ornithischia (1), Tyreophora (2, light-green), Cerapoda (3), Marginocephalia (4), Ceratopsia (5, light-blue), Pachcephalosauria (6, violet), Ornithopoda (7).

\section{Results}

Running the analysis with the a posteriori pruning of Yandusaurus hongheensis results in 176 MPTs. The strict consensus tree ( $\mathrm{CI}=0.295, \mathrm{RI}=0.615,1426$ steps $)$ is our reference tree for the discussion.

Chilesaurus diegosuarezi (Novas et al. 2015; Baron and Barrett 2017) is recovered as the basalmost ornithischian. C. diegosuarezi, Laquintasaura venezuelae (Barrett et al. 2014) and Lesothosaurus diagnosticus (Baron et al. 2016) are recovered as successive sister taxa at the base of Genasauria. Isaberrysaura mollensis (Salgado et al. 2017) is the sister taxon of Stegosauria. Eocursor parvus (Butler et al. 2007; Butler 2010) is found at the base of Neornithischia. Heterodontosaurids are recovered as basal members of Cerapoda, as previously suggested by a few studies (e.g. Cooper 1985; Weishampel and Heinrich 1992; Salgado et al. 1997; Norman et al. 2004; Calvo et al. 2007). They form a paraphyletic grade of taxa stemming 'true' pachycephalosaurs and should, therefore, be regarded as the basalmost members of Pachycephalosauria sensu Sereno, 1998, defined as all marginocephalians closer to
Pachycephalosaurus than to Triceratops. The arbitrary positioning of a monophyletic 'Heterodontosauridae' at the base of Genasauria was found as significantly different from the optimal tree in the Templeton Test with 38 extra steps (cf. Supplemental Material 6), which supports their newly recovered topology. As in Sereno (2012), we recover the monophyletic subfamily Heterodontosaurinae that groups Abrictosaurus consors, Heterodontosaurus tucki and Lycorhinus angustidens. Fruitadens haagarorum is recovered as rooting Heterodontosaurinae, while Tianyulong confuciusi and Echinodon becklesii are recovered as successive outgroup taxa to dome-headed, 'true' pachycephalosaurs. The clade comprising the derived 'eupachycephalosaurs' Prenocephale prenes, Pachycephalosaurus wyomingensis, Homalocephale calathocercos and Stegoceras validum form a polytomy in the strict consensus tree.

The ornithopods Nanosaurus agilis, Changchunsaurus parvus, Jeholosaurus shangyuanensis, Haya griva, a clade composed of Zephyrosaurus schaffi, Orodromeus makelai and Koreanosaurus boseongensis, and Kulindadromeus zabaikalicus are recovered as successive sister taxa outside Clypeodonta. 


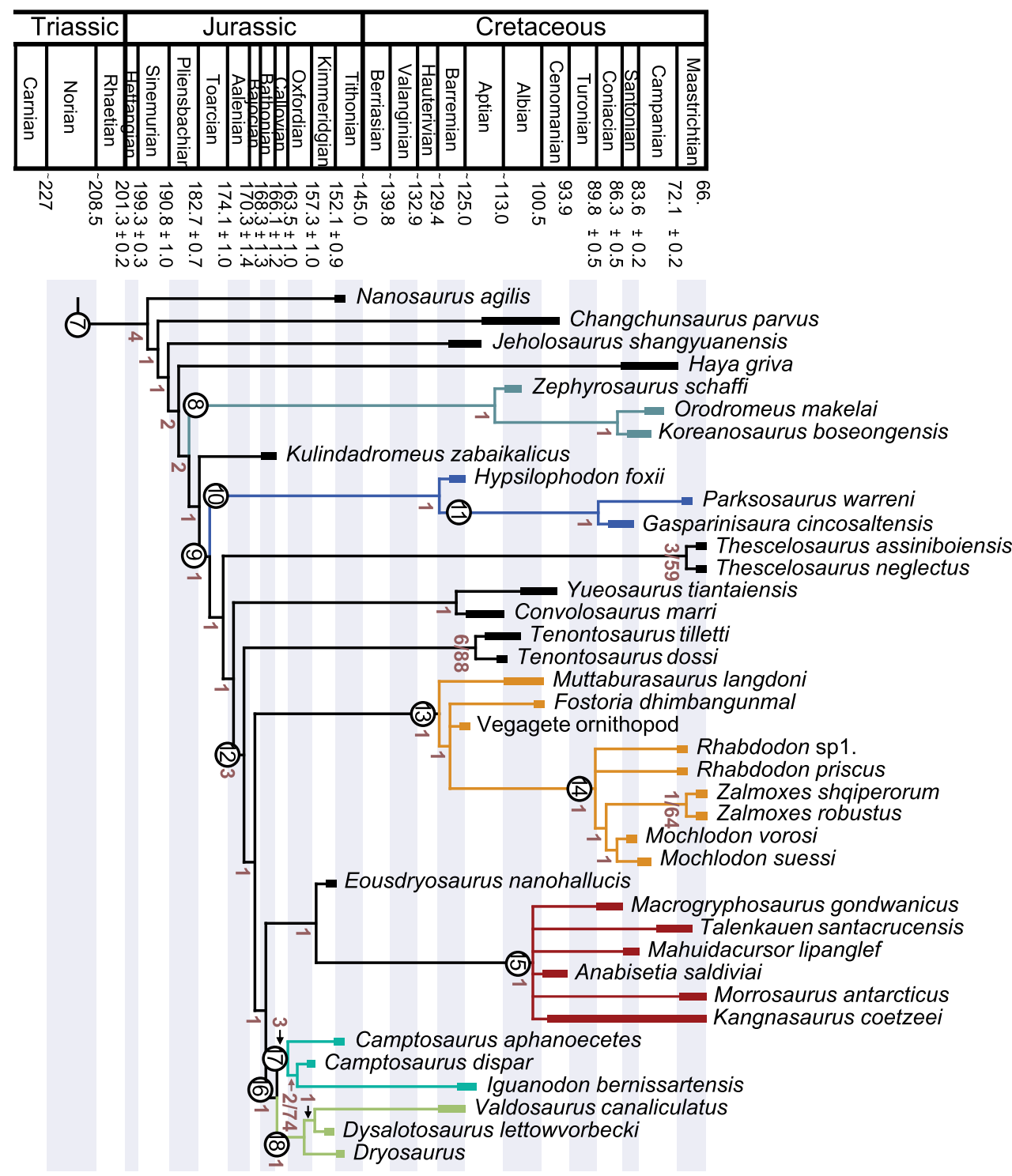

Figure 2. Strict consensus tree calibrated over the chronostratigraphic timescale of Cohen et al. (2013, updated version), showing relationships within Ornithopoda. The analysis was run under equally-weighted parsimony with the a posteriori removal of Yandusaurus hongheensis. Bremer supports are reported below each node. Bootstrap values are also added to the right of the Bremer indices whenever those are superior to $50 \%$. Specific clades are shown with a circled number, and some of them highlighted using a specific colour: Ornithopoda (7), Orodrominae (8), Clypeodonta (9), Hypsilophodontidae (10, blue) and Parksosauridae (11, included within the latter, dubious Hypsilophodontidae), Iguanodontia (12), Rhabdodontomorpha (13), Rhabdodontidae (14), Elasmaria (15), Dryomorpha (16), Ankylopollexia (17, turquoise) and Dryosauridae (18, light-green).

Hypsilophodon foxii is recovered in monophyly with another subclade formed by Parksosaurus warreni and Gasparinisaura cincosaltensis. This whole group is dubious and falls within a weakly supported Hypsilophodontidae sensu Boyd (2015). Concerning iguanodontian ornithopods, our phylogenetic result is similar to that found earlier by Calvo et al. (2007) and Barrett et al. (2011). Elasmaria is formally defined as Talenkauen santacrucensis, Macrogryphosaurus gondwanicus, their common ancestor and all of their descendants (Calvo et al. 2007). Consistently with earlier analyses (Cruzado-Caballero et al. 2019; Rozadilla et al. 2019), elasmarians are recovered as an intrinsically unresolved but separate lineage of gondwanan iguanodontians. As already suggested by Escaso et al. (2014), we find them as probably stemming from an early shoot of Late Jurassic dryosauroid-like ornithopods, with E. nanohallucis as their closest outgroup.

Herne et al. (2019); Bell et al. (2019) and Madzia et al. (2020) suggested more exclusive affinities between Muttaburrasaurus langdoni, Fostoria dhimbangunmal and basal dryomorphs. Despite earlier criticisms (Herne et al. 2019; Bell et al. 2019), the clade Rhabdodontomorpha finds renewed support as a monophyletic group in our analysis (Figure 2). The arbitrary positioning of Rhabdodontomorpha as the closest sister-taxon of Ankylopollexia implies 13 extra-steps with respect to the strict consensus. This is more than what would be expected from sampling error: this alternative topology is therefore not supported by our data matrix $(0.01<\mathrm{p}<0.025$, Supplemental Material 6$)$. By contrast, the artificial splitting of Rhabdodontomorpha with $M$. langdoni and F. dhimbangunmal set as a monophyletic sister group of Ankylopollexia and rhabdodontids left as basal iguanodontians is an alternative solution that is plausible with respect to the strict consensus (11 extra steps, $\mathrm{p}>0.05$, Supplemental material 6). However, we remark that the sum of negative ranks - which favours the alternative hypothesis (Templeton 1983) - stands only very close to the upper limit corresponding to a p-value of 0.05 (Supplemental material 3), so this alternative result has no strong support. 


\section{Discussion}

\section{Heterodontosauridae: a controversial origin as basal ornithischians}

According to Butler et al. (2008) and Galton (2014), the skeleton of heterodontosaurids is characterised by a series of plesiomorphic characters that are also present in the basal saurischian Herrerasaurus ischigualastensis, thus justifying their basal rooting within Ornithischia. Among these, we find the presence of unexpanded premaxillary crowns (\#113 in Butler et al. 2008), a v-shaped dentary symphysis (\#97 in Butler et al. 2008), and the presence of epipophyses on the anterior cervicals (\#133 in Butler et al. 2008). The manus of heterodontosaurids and $H$. ischigualastensis also shares synapomorphies that are all likely related with enhanced grasping capabilities: a manus length that is more than $40 \%$ the combined length of the humerus and radius (\#156 in Butler et al. 2008), elongate penultimate phalanges of the second and third manual digits (\#159 in Butler et al. 2008), the presence of extensor pits on the distal metacarpals and manual phalanges (\#162 in Butler et al. 2008) and strongly recurved manual unguals with prominent flexor tubercles (\#163 in Butler et al. 2008). However, we consider the coding of some of those characters controversial. For example, the dentary symphysis of $H$. ischigualastensis is straight, unexpanded and restricted to its very distal tip (Sereno and Novas 1993, Figure 1(f)), which is in marked contrast with the massively buttressed and $\mathrm{v}$-shaped symphysis of Heterodontosaurus tucki (Norman et al. 2011, appendix 6.D). The humerus of $H$. ischigualastensis is incompletely preserved, so the relative proportion of its manus with respect to its humerus and radius cannot be adequately assessed (Sereno 1993, figs. 3-4). Finally and in contrast to heterodontosaurids, the penultimate phalanges of fingers II and III are not longer than those from the first row in H. ischigualastensis (Sereno 1993, fig. 13 and 15).

Some incongruences were subsequently raised, e.g. by Barrett and Maidment (2011) and Porro et al. (2015) about the basal positioning of heterodontosaurids as hypothesised by Butler et al. (2008). Early Jurassic heterodontosaurids are characterised by closely packed and chisel-shaped maxillary and dentary teeth, as well as by a higher coronoid process (Sereno 2012) all of which are highly atypical for basal ornithischians (Porro et al. 2015, p. 2). Barrett and Maidment (2011) also pointed out that the basal rooting of heterodontosaurids enforced important homoplasies concerning the evolution of the ornithischian pelvis. A prominent and laterally projecting supra-acetabular crest encloses the femoral head into a cup-shaped structure in all advanced archosaurs and basal ornithischians having achieved an upright limb-posture (Charig 1972). This supra-acetabular crest was subsequently lost in neornithischians more derived than Agilisaurus louderbacki (e.g. Peng 1992, Figure 5) as an improvement of their bipedal stance. The insertion of their adductor limb musculature probably shifted from their well-developped preacetabular process of ilium towards a secondarily developed prepubic process (Charig 1972). As Barrett and Maidment (2011) pointed out, heterodontosaurids are unusual basal ornithischians in that they already lost their supraacetabular crest of the ilium and developed a stub-like prepubic process.

Several authors already noticed that heterodontosaurids shared synapomorphies with marginocephalians. Among these are the presence of three premaxillary teeth (Norman et al. 2011; Han et al. 2015) or the loss of the ischial obturator process (Galton 2014). More recently, Becerra and Pol (2020) identified interesting correspondences in the enamel microstructure of the heterodontosaurid Manidens condorensis and pachycephalosaurids, both featuring the presence of incipient divergent crystallite units devoid of clear mutual limits, followed by an outer layer of parallel/divergent crystallites. Similar enamel types were also found in more basally branching tyreophorans and sauropodomorphs (Becerra and Pol 2020).

\section{A review of Marginocephalia}

\section{Marginocephalia: an historically weakly supported clade}

The first diagnoses of Marignocephalia were proposed by Sereno (1984, 1986, 2000) and Maryanska and Osmolska (1985). The

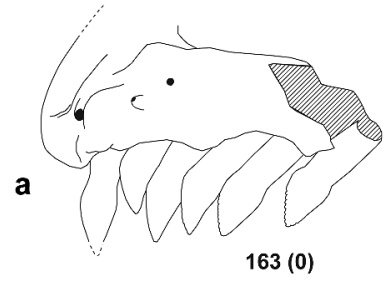

$163(0)$

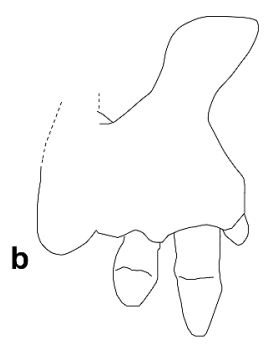

$163(1)$
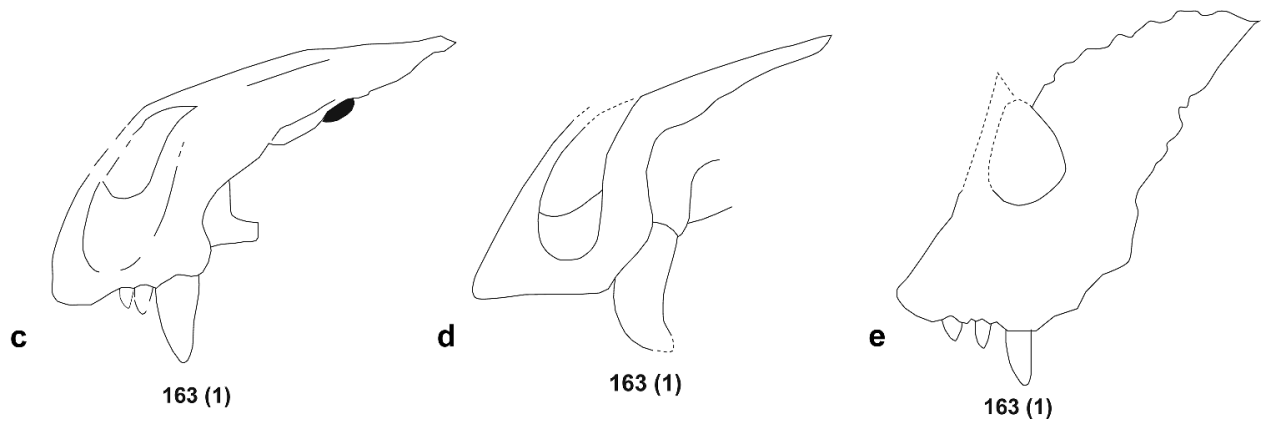

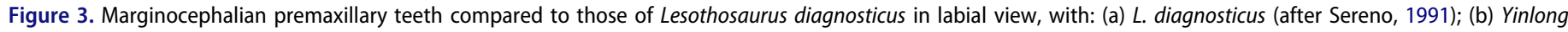

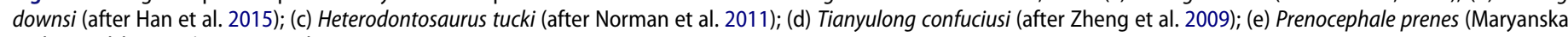
and Osmolska 1974). Not to scale. 
a
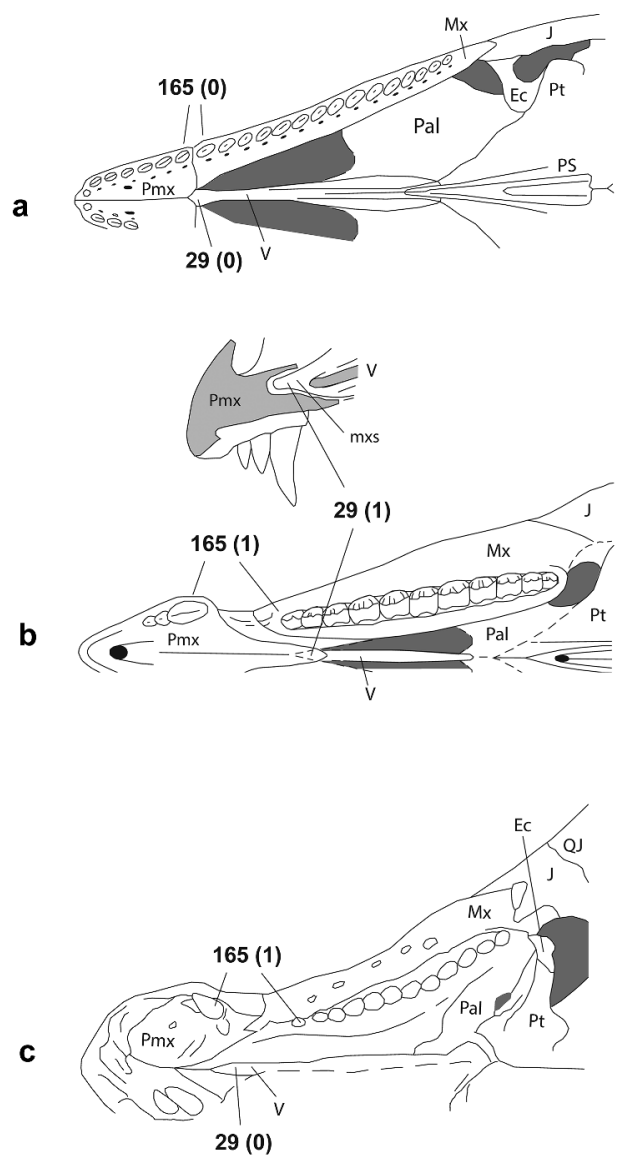

d

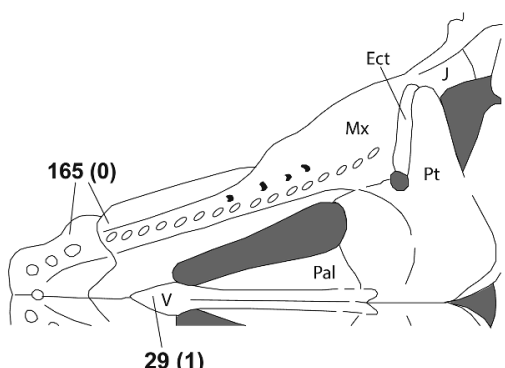

29 (1)

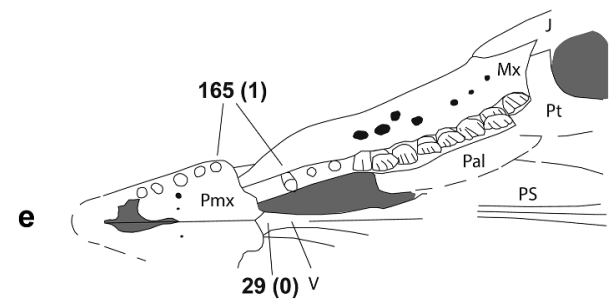

f

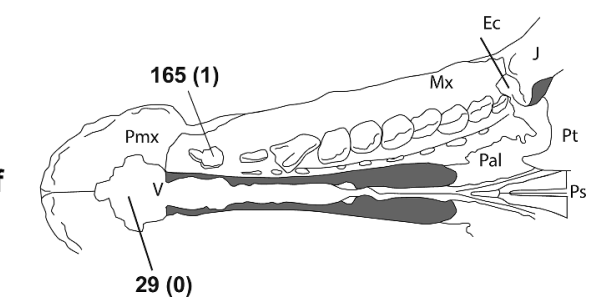

Figure 4. Marginocephalians snouts compared to those of other ornithischians in ventral view, with: (a) Lesothosaurus diagnosticus (after Sereno, 1991), (b) Heterodontosaurus tucki (after Norman et al. 2011); (c) Liaoceratops yanzigouensis (after Xu et al. 2002); (d) Stegoceras validum (after Sues and Galton 1987); (e) Hypsilophodon foxii (after Galton 1974a); (f) Tenontosaurus tilletti (after Thomas 2015). Abbreviations: Ec, Ectopterygoid; J, jugal; Mx, maxilla, mxs, intermaxillary suture; Pal, palatine; Pmx, premaxilla; PS, parasphenoid; Pt, pterygoid; QJ, quadratojugal; V, vomer. Not to scale.

number of synapomorphies for the clade went progressively reduced throughout the years from nine (Sereno 1984) to three (Sereno 2000). These three characters are: (1) the posterior extension of a parietosquamosal shelf obscures the occiput from a dorsal view, (2) a median contact between the maxillae excludes the premaxillae from participation to the anterior margin of internal nares, (3) the postpubic process is short and lacks a distal pubic symphysis. However, in the light of new descriptions and discoveries, we consider that solely one of these characters is valid.

We agree with Sues and Galton (1987) that the parietosquamosal shelf of ceratopsians shows no close resemblance with that of pachycephalosaurs. As already noticed by Sereno (2000), the relative contribution of the parietal and squamosal to the parietosquamosal shelf is different in both clades. In pachycephalosaurs, the parietal shelf is anteroposteriorly thick, and the parietal contribution to the parietosquamosal shelf is narrow (e.g. Stegoceras validum, Gilmore 1924, pl., 4). In ceratopsians, the parietal shelf consists in a dorsoventrally wide and anteroposteriorly thin strap of bone (e.g. Archaeoceratops oshimai and Yinlong downsi, You and Dodson 2003; Han et al. 2015). Moreover, the occiput is still visible from a dorsal view in basal ceratopsians (e.g. Yinlong downsi, Han et al. 2015, Figure 4(b)). The second character deals with the anterior contact of the internal nare - that is enclosed by the paired vomers - with the mutually contacting maxillae. As will be discussed below this character remains a marginocephalian synapomorphy even considering our new tree topology, as it is also present in heterodontosaurids (Norman et al. 2011, Figure 11). Yet, our formulation of this character slightly differs from that of Sereno's (2000) as we consider the vomeral head instead of the internal nare (\#29) for the anterior contact with the paired maxillae. We concur with Sereno (2000) in that a postpubic reduction is shared by ceratopsians (You and Dodson 2004) and Homalocephale calathocercos, the only 'true' pachycephalosaur in which a broken but likely very short postpubis is known (Maryanska and Osmolska 1974, Figure 5(b)). However, the placement of Heterodontosauridae within Pachycephalosauria as suggested in the present analysis leads us to reconsider the postpubic reduction as independently acquired in both the pachycephalosaurian and the ceratopsian lineages.Tianyulong confuciusi (Zheng et al. 2009) is the only non-heterodontosaurine pachycephalosaur that preserves a complete postpubis and that clearly shows a post-pubic reduction. The postpubic process is as long as the ischium in Heterodontosaurus tucki (Galton 2014) and Manidens condorensis (Pol et al. 2011). The post-pubic reduction occurred several times independently within Ornithischia: in addition to pachycephalosaurs and ceratopsians, it also occurred in ankylosaurs (Vickaryous et al. 2004), iguanodontoids (Norman 2004) and hadrosaurids (Horner et al. 2004).

\section{Synapomorphies of Marginocephalia}

The main result of the phylogenetic analysis proposed in the present paper is the placement of heterodontosaurids as a paraphyletic group of basal marginocephalians closer to 'true' pachycephalosaurs than to Ceratopsia. This hypothesis significantly increases the number of synapomorphies shared by Marginocephalia. Sereno (1998) defines pachycephalosaurs as all marginocephalians 
a

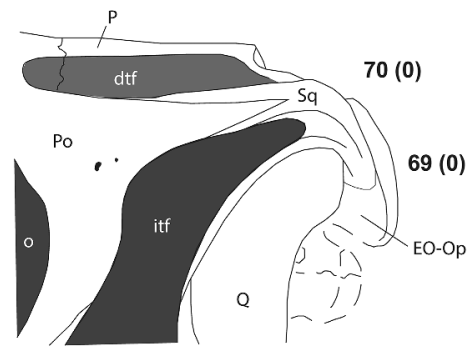

b
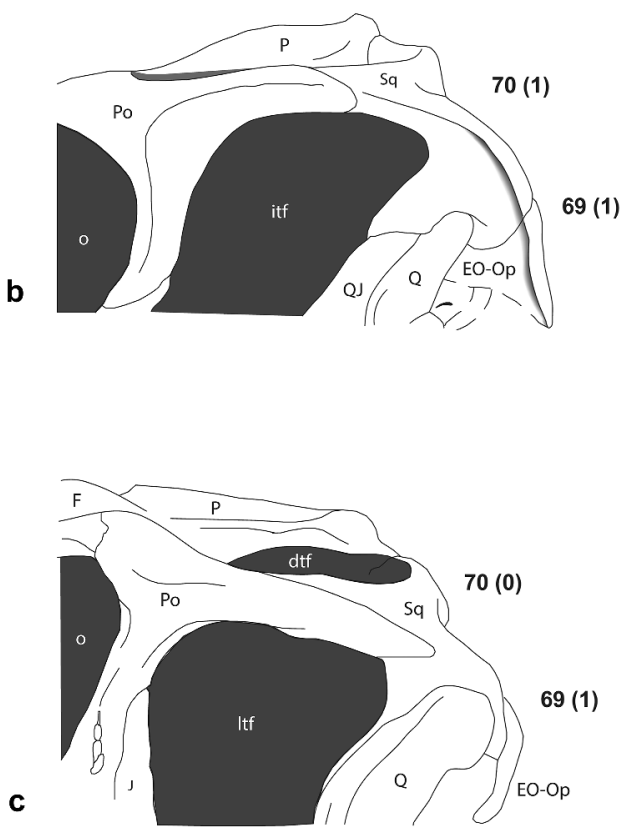

(1)
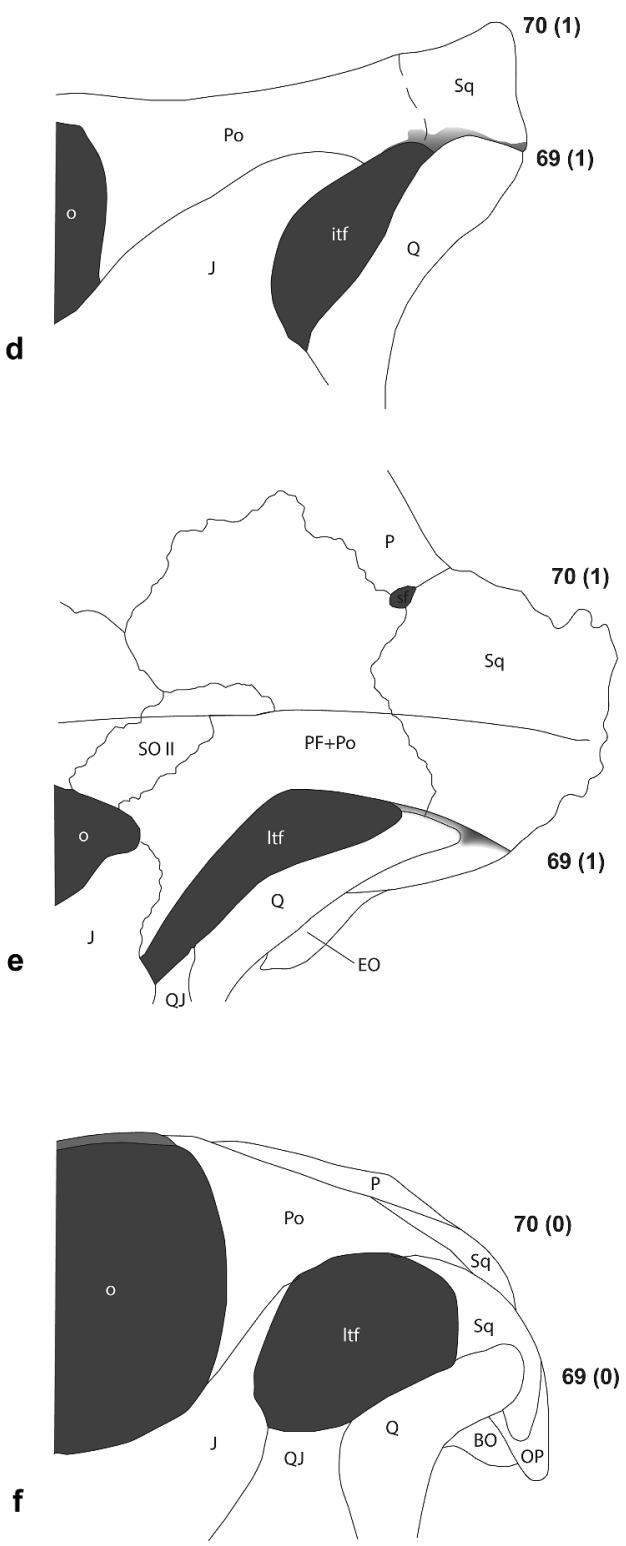

Figure 5. Marginocephalians squamosals compared to those of other ornithischians in lateral view, with: (a) Lesothosaurus diagnosticus (after Sereno, 1991); (b) Heterodontosaurus tucki (Norman et al. 2011); (c) Psittacosaurus major (after You et al. 2008, fig. 1B1); (d) Archaeoceratops oshimai (after You and Dodson 2003); (e) Stegoceras validum (Sues and Galton 1987); ( $\mathrm{f}$ Hypsilophodon foxii (Galton 1974a). Abbreviations: BO, basioccipital; Eo-Op, exoccipital-opisthotic; sf, supratemporal fenestra; if, infratemporal fenestra; J, jugal; o, orbit; OP, opisthotic; P, parietal; Po, postorbital; SOll, supraorbital II; Q, quadrate; QJ, quadratojugal; Sq, squamosal. Not to scale.

closer to Pachycephalosaurus than to Triceratops. According to this definition and to their phylogenetic position in the present analysis, 'heterodontosaurids' should, therefore, be regarded as basal members of Pachycephalosauria. 'Heterodontosaurids' lack the typically thickened squamosals and frontoparietal of formerly referred 'true' pachycephalosaurs (e.g. Sereno 2000). We will therefore informally refer to those marginocephalians fitted with a thickened dorsal skull roof as 'eupachycephalosaurs'. The paraphyletic 'sabre-toothed' pachycephalosaurs devoid of a thickened dorsal skull roof will be referred to here as 'heterodontosaurids' between quote marks because this group is paraphyletic according to this analysis. The newly recovered synapomorphies for Marginocephalia are listed and discussed below.

(1) The presence of three premaxillary teeth (\#159, Figure 3) is shared by Heterodontosaurus tucki (Figure 3(c), Norman et al. 2011, fig. 20), Abrictosaurus consors (Sereno 2012, fig. 31), Echinodon becklesii (Sereno 2012, Figure 13(c-d), 19),
Fruitadens haagarorum (Butler et al. 2012, Figure 1), Archaeoceratops oshimai (You and Dodson 2003, p. 264), Liaoceratops yanzigouensis (Xu et al. 2002), Yinlong downsi (Han et al. 2015) and eupachycephalosaurs (Figure 3(e), Maryanska and Osmolska 1974, fig. 1A1, C1; Perle et al. 1982, p. 118). Those three premaxillary teeth were later lost progressively and possibly also several times within Marginocephalia: Chaoyangsaurus youngi has two premaxillary teeth (Zhao et al. 1999), psittacosaurids (e.g. Sereno 2010) and Protoceratops andrewsi (Brown and Schlaikjer 1940) have none and Tianyulong confuciusi has two premaxillary teeth (Sereno 2012).

(2) The presence of a posterior caniniform premaxillary tooth (\#163, Figure 3) and an anterior caniniform dentary tooth (\#184) are outstanding features commonly found in nearly all 'heterodontosaurids', except in Abrictosaurus consors (Sereno 2012, fig. 34, 35). Caniniform premaxillary and dentary teeth are also found in the primitive eupachycephalosaur 
Goyocephale lattimorei (Perle et al. 1982, pl. 42.5, 42.9). Hou (1977, p. 3) cited an anterior caniniform dentary tooth in Wannanosaurus yansiensis that is now unfortunately lost (Butler and Zhao 2009). Its apex was not completely freed from the matrix at the time of its description, and the whole tooth did not appear significatively enlarged apicobasally (Hou 1977, Figure 1). A posterior increase in the size of premaxillary tooth crowns is also observed in Prenocephale prenes (Figure 3(e), Maryanska and Osmolska 1974, pl. 23.1C) and in the primitive ceratopsian Yinlong downsi (Figure 3(b), Han et al. 2015, fig. 21A).

(3) The presence of a premaxilla-lacrimal contact (\#17) is shared by Heterodontosaurus tucki (Norman et al. 2011, Figure 8), Tianyulong confuciusi (Sereno 2012, p. 55), psittacosaurids (Sereno 2010, fig. 2.3, 2.7) and Yinlong downsi (Xu et al. 2006 \#34; Han et al. 2015, Figure 8(b)).

(4) Another potentially important synapomorphy of Marginocephalia is an anterior midline contact between both maxillae that prevents the vomer from contacting the premaxillae (\#29, Figure 4). As discussed above, a slightly different version of this character was already identified as a synapomorphy for Marginocephalia by Sereno (2000). It is actually observed in nearly all marginocephalians - with the possible exception to the basal ceratopsian Yinlong downsi in which this midline contact is dubious and possibly absent. A midline exclusion of the anterior vomeral head from the paired premaxillae is apparent in the pachycephalosaurs Goyocephale lattimorei (Perle et al. 1982, pl. 41.3B), Prenocephale prenes and Stegoceras validum (Figure 4(d), Maryanska and Osmolska 1974, fig. 1A3, C3), but also in the ceratopsians Liaoceratops yanzigouensis (Figure 4(c), $\mathrm{Xu}$ et al. 2002, Figure 1(d)). In Heterodontosaurus tucki, the vomer would intercede in the complex interlocking joint prior to an intermaxillary contact, at a level dorsal to the ventral premaxillary branches, so a premaxillary-vomeral contact would be absent (Figure 4(b), see also Norman et al. 2011, p. 204, fig. 10, 11). In Psittacosaurus major, 'the vomer attaches to the dorsal surface of the maxillary symphysis' so we infer that there is a maxillary symphysis that prevents the vomer from contacting the premaxillae (You et al. 2008, p. 190). In Y. downsi, Han et al. (2015, p. 11) observes that 'the diamond-shaped rostral part of the vomers underlies and intercedes a short distance between the premaxillae at the rear of the premaxillary palate'. They further mention that 'the medial aspect of the articular peg [of maxilla] extends medial to the body of the maxilla; its surface is striated for articulation with either the vomer or contralateral maxilla' (Han et al. 2015 , p. 12). They add that the intermaxillary contact is not visible in ventral view but could have occurred 'deep to the vomer' (Han et al. 2015, p. 12). This description recalls the complex interlocking contact of the vomeral head posteriorly with the short intermaxillary suture in $H$. tucki, which is only visible from a sagittal section but not from a mere ventral view (Figure 4(b)). There remains a possibility that the vomeral contact of $Y$. downsi resembles that of $H$. tucki, although this cannot be ruled out from the available descriptions.

(5) Heterodontosaurus tucki (Norman et al. 2011, appendix 3A, 4A-B), Manidens condorensis ( $\mathrm{Pol}$ et al. 2011, Figure 2(ab)), Yinlong downsi (Han et al. 2015, fig. 3(a), 5(a), 8(a)), Psittacosaurus major (You et al. 2008, Figure 1(b)), Wannanosaurus yansiensis, Prenocephale prenes,
Stegoceras validum, Homalocephale calathocercos (Maryanska and Osmolska 1974, fig. 1A4, C4, D4), Goyocephale lattimorei (Perle et al. 1982, pl. 42.1), Pachycephalosaurus wyomingensis (Brown and Schlaikjer 1943, pl. 39), all have squamosals with a varyingly developed dorsolateral overhang (\#69, Figure 5(b,c,e)). Such a lateral overhang seems to have been reduced convergently and might have expanded down to the quadrate cotylus in basal neoceratopsians Archaeoceratops oshimai (Dong and Azuma 1997, Figure 2(a); You and Dodson 2003, Figure $1(\mathrm{e})$ ) and Liaoceratops yanzigouensis (Xu et al. 2002, Figure 1(a,c)).

(6) The squamosal is high and its posterodorsal margin is set away from the quadrate cotylus (\#70, Figure 5) in Heterodontosaurus tucki (Norman et al. 2011, Appendix 3A, 4A-B), Manidens condorensis (Pol et al. 2011, Figure 2 (a-b)), Yinlong downsi (Han et al. 2015, fig. 3(a), 8(a)), Archaeoceratops oshimai (Figure 5(d), You and Dodson 2003, Figure 1(a,c)), Liaoceratops yanzigouensis (Xu et al. 2002, Figure 1(a,b)), Wannanosaurus yansiensis (Butler and Zhao 2009, Figure 5(c)), Prenocephale prenes, Homalocephale calathocercos, Stegoceras validum (Figure 5(e), Maryanska and Osmolska 1974, fig. 1A4, C4, D4), Pachycephalosaurus wyomigensis (Brown and Schlaikjer 1943, pl. 39). Note that the squamosal-quadrate articulation is set close to the posterodorsal border of the squamosal in psittacosaurids (Figure 5(c), You et al. 2008; Sereno 2010, fig. 2.7).

(7) The angular reaches the dorsal margin of the mandibular ramus (\#157, Figure 6) in the ceratopsians Archaeoceratops oshimai (You and Dodson 2003, Figure 1(a-c); Tanoue et al. 2010, fig. 16.3), Liaoceratops yanzigouensis (Xu et al. 2002, Figure 1(a-b)), Chaoyangsaurus youngi (Zhao et al. 1999, Figure 2(a)), and the pachycephalosaurs Heterodontosaurus. tucki (Figure 6(d), Norman et al. 2011, Fig. 19A), Manidens condorensis (Pol et al. 2011, Figure 2(c)), Tianyulong confuciusi (Zheng et al. 2009, Figure 1(d)), Stegoceras validum (Figure 6(c), Gilmore 1924, pl. 1). In Yinlong downsi, the angular reaches the upper mandibular margin in the left side of IVPP V14530 and both sides of IVPP V18636 and IVPP V18686 (Han et al. 2015, fig. 3, 8(a), 11(a) respectively), but not in the right side of IVPP V14530 (Han et al. 2015, Figure 2). In any case, $Y$. downsi is also characterised by a dorsoventrally tall angular as in the aforementioned taxa. The angular is more than half the height of the mandibular ramus but does not reach its upper level in derived psittacosaurids (You et al. 2008, Figure 4; Sereno 2010, fig. 2.7).

(8) Marginocephalians uniquely share the presence of 12 to 13 dorsal vertebrae (\#203). This condition was actually reported in the ceratopsians Archaeoceratops oshimai (Dong and Azuma 1997, p. 78), Yinlong downsi (Han et al. 2018, Figure 2(a)), Psittacosaurus mongoliensis (Hailu and Dodson 2004, p. 487), but also in the basal pachycephalosaur Heterodontosaurus tucki (Galton 2014, Figure 6(b)).

(9) The marginocephalians Yinlong downsi (Han et al. 2018, Figure 5), Heterodontosaurus tucki (Galton 2014, Figure 3 (a)) and Stegoceras validum (Gilmore 1924, pl. 9.1) have elongated and strap-like scapulae, i.e. that is more than nine times as long as its minimum width at the level of the scapular neck (\#224, Figure 7(b,d,e)). We shall remark that the scapula is not strap-like in Psittacosaurus 

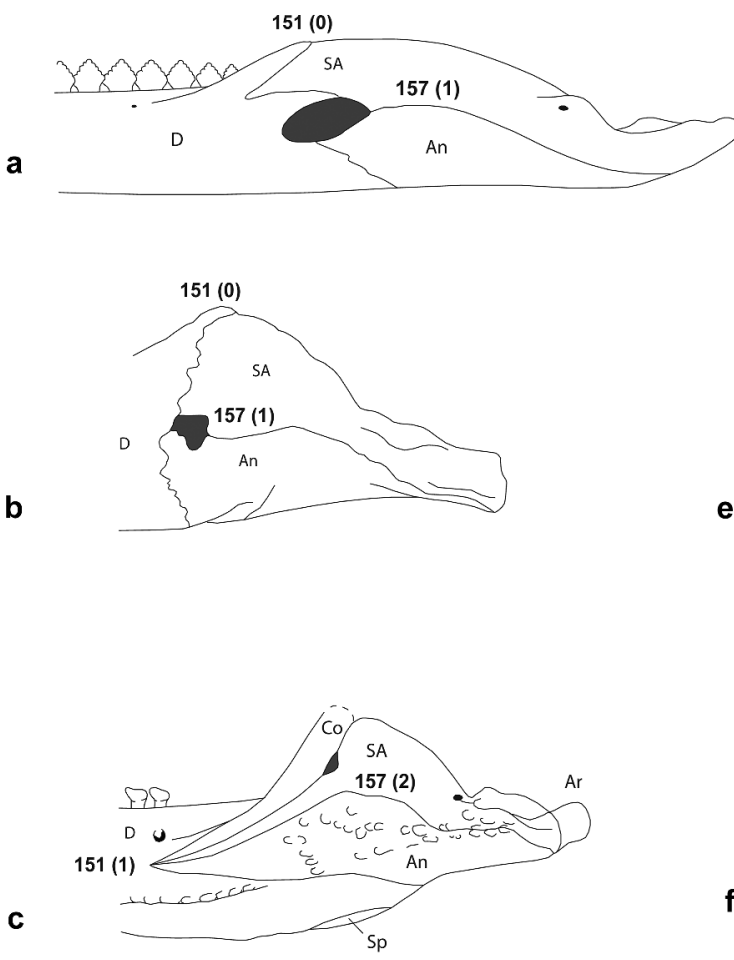
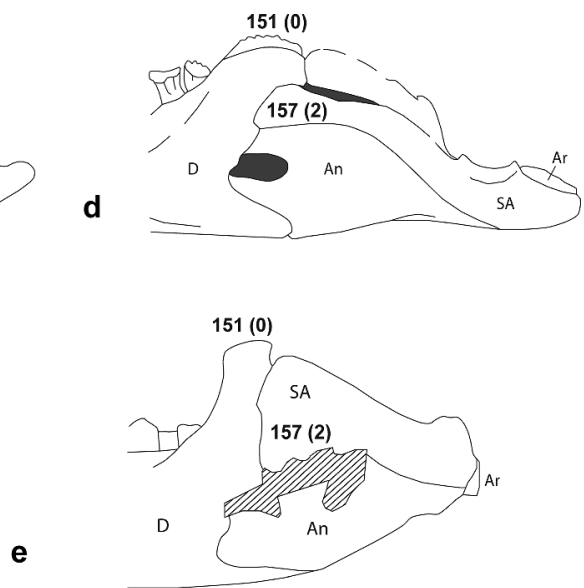

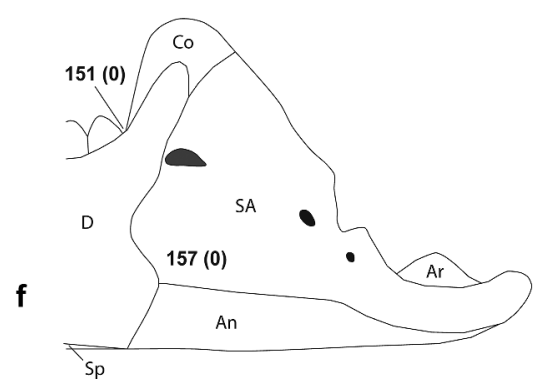

Figure 6. Marginocephalians lower jaws compared to those of other ornithischians in lateral view, with: (a) Lesothosaurus diagnosticus (after Sereno, 1991); (b) Psittacosaurus mongoliensis (after Sereno 2010); (c) Stegoceras validum (after Sues and Galton 1987); (d) Heterodontosaurus tucki (after Norman et al. 2011); (e) Archaeoceratops oshimai (after Tanoue et al. 2010); (f) Hypsilophodon foxii (after Galton 1974a). Abbreviations: An, angular; Ar, articular; Co, coronoid; D, dentary; SA, surangular; Sp, splenial. Not to scale.

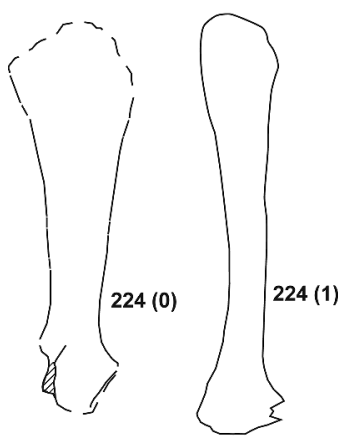

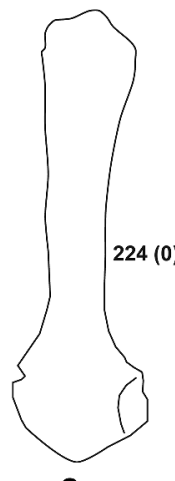

C

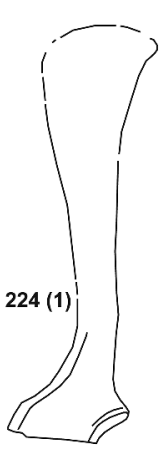

d

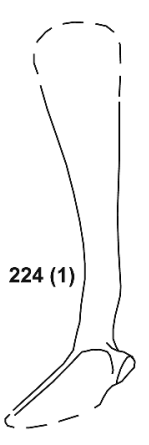

e
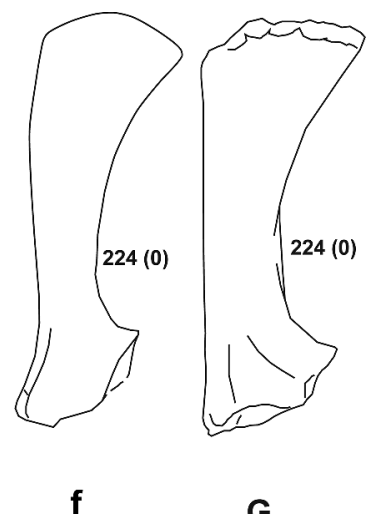

G

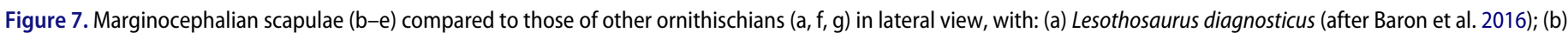

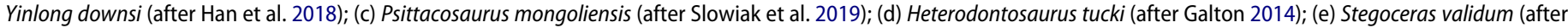
Sues and Galton 1987; reversed)); (f) Hypsilophodon foxii (after Galton 1974a); (g) Tenontosaurus tilletti (after Forster 1990). Not to scale.

mongoliensis (Senter 2007, Figure 3(j); Slowiak et al. 2019, Figure 4(i)).

(10) The postpubic shaft and prepubic process are widely open and their axes are nearly parallel to each other in all marginocephalians in which this character can be observed (\#283, Figure 8). This is notably the case in the ceratopsians Psittacosaurus mongoliensis (Figure 8(c), Osborn 1924, Figure 8) and Yinlong downsi (Han et al. 2015, Figure 11 (e)), and in the basal pachycephalosaur Heterodontosaurus tucki (Figure 8(d), Galton 2014, Figure 12(f-g)). This feature cannot be observed in any other more derived pachycephalosaur. In Homalocephale calathocercos, the postpubic shaft is broken a few millimetres past the articulation with the ischium, but its proximal portion appears extremely reduced (Maryanska and Osmolska 1974, fig. 5A5-8).

(11) As previously suggested by Gilmore (1924), the total absence of an ischial obturator process is an apomorphy of Marginocephalia (\#292, Figure 9). The ischium of Yinlong downsi has a 'plate-like' distal expansion (Figure 9(b), Han et al. 2018, Figure 11(e,g)), but no real obturator process. Archaeoceratops oshimai (Figure 9(c), Dong and Azuma 1997, Figure 7), Psittacosaurus mongoliensis (Figure 9(d), Osborn 1924, Figure 8), Stenopelix valdensis (Butler 
b

a

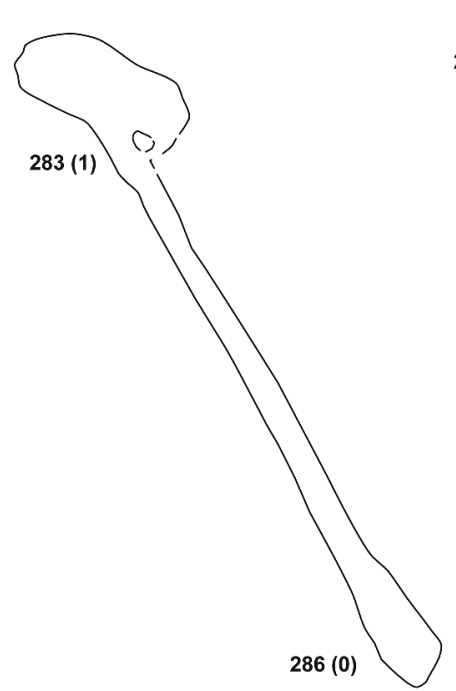

d

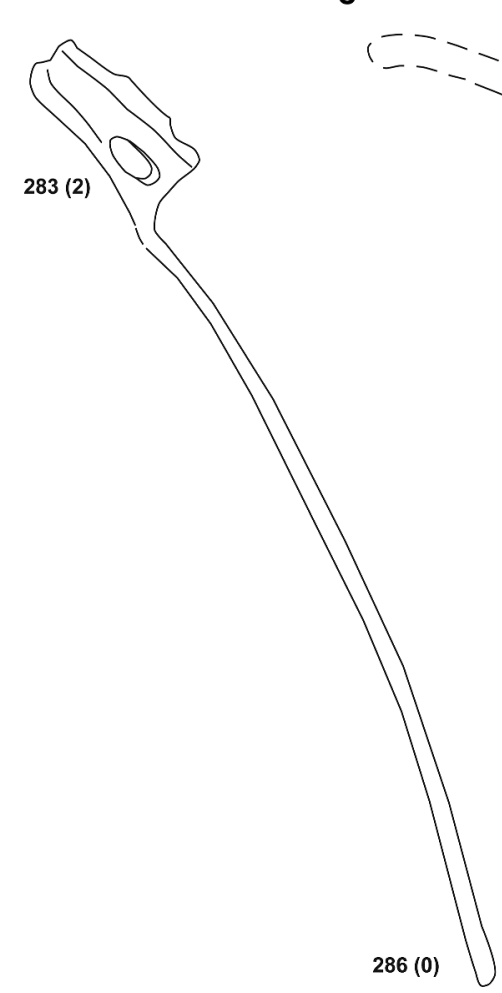

C

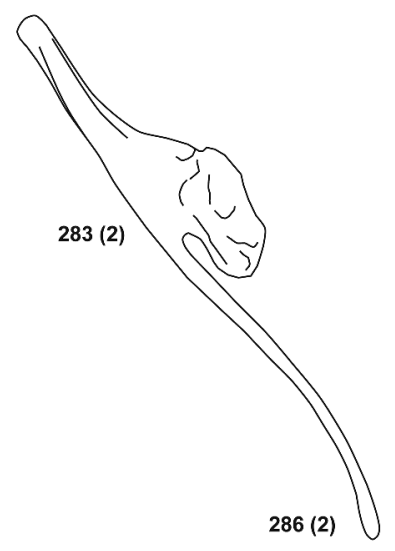

f

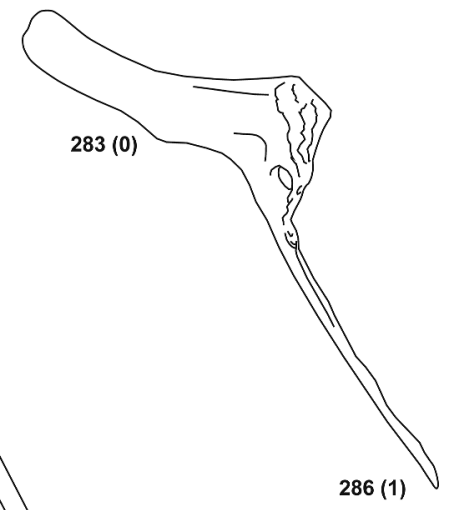

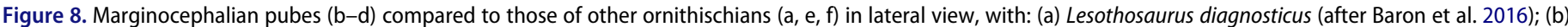

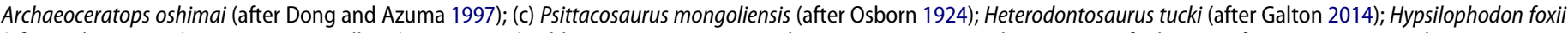
(after Galton 1974a); Tenontosaurus tilletti (Forster 1990). Abbreviations: pop, postpubic process; prp, prepubic process; of, obturator foramen; Not to scale.

and Sullivan 2009, Figure 3), Prenocephale prenes (Maryanska and Osmolska 1974, pl. 25.3B), Stegoceras validum (Figure 9(f), Gilmore 1924, p. 35, pl. 10.3), and also the 'heterodontosaurids' Heterodontosaurus tucki (Figure 9(e), Galton 2014, Figure 9(j)) and Tianyulong confuciusi (Zheng et al. 2009, supp. info. p. 5) all lack a tabshaped obturator process.
(12) The main axis of the proximal ischial shaft is parallel to the main axis of the pubic peduncle (\#289, Figure 8 ). This character is reported in Heterodontosaurus tucki (Galton 2014, Figure 12(f,g)), Manidens condorensis (Pol et al. 2011, Figure 1(a-b)), Stegoceras validum (Figure 8(f), Gilmore 1924, Figure 3(a)), Prenocephale prenes and Homalocephale calathocercos (Maryanska and Osmolska 1974, pl. 25.3B 


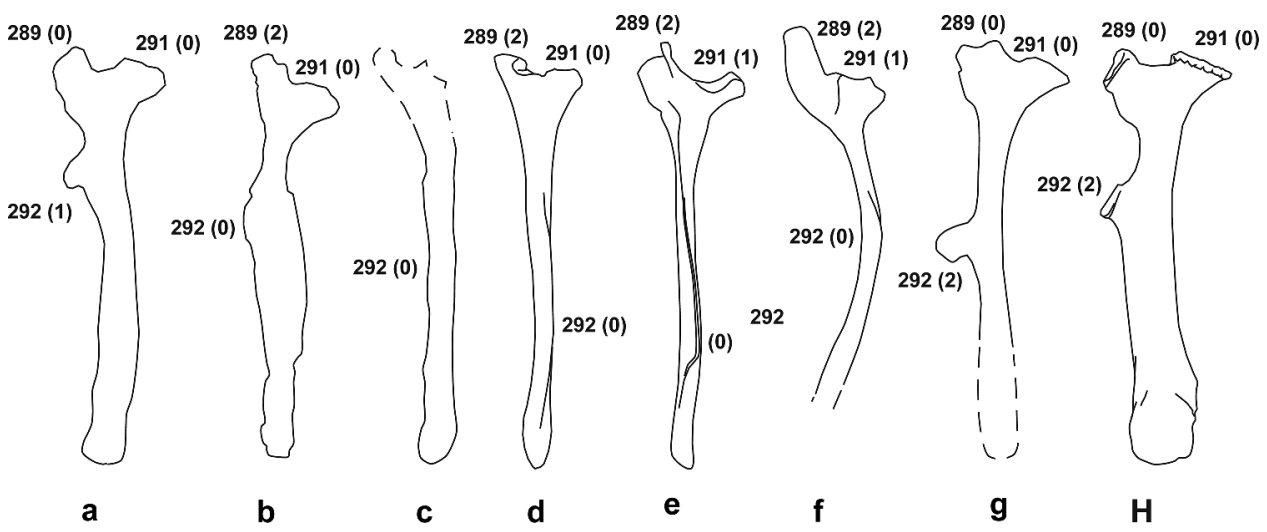

Figure 9. Marginocephalian ischia (b-f) compared to those of other ornithischians (a, $g, h$ ) in lateral view, with: (a) Lesothosaurus diagnosticus (after Baron et al. 2016); (b) Yinlong downsi (after Han et al. 2018); (c) Archaeoceratops oshimai (after Dong and Azuma 1997; reversed); (d) Psittacosaurus mongoliensis (after Osborn 1924; reversed); (e) Heterodontosaurus tucki (after Galton 2014); (f) Stegoceras validum (after Gilmore 1924); (g) Hypsilophodon foxii (after Galton 1974a); Tenontosaurus tilletti (after Forster 1990). Not to scale.

and pl. 29 respectively), Yinlong downsi (Figure 9(b), Han et al. 2018, Figure 11(e,g)), Psittacosaurus mongoliensis (Figure 9(d), Osborn 1924, Figure 8), and Stenopelix valdensis (Butler and Sullivan 2009, Figure 3).

\section{Heterodontosauridae and the origins of Pachycephalosauria} Pachycephalosaurs ('Heterodontosauridae' and Eupachycephalosauria) are grouped together based on the following synapomorphies.

(1) Braincases are rarely observable, unless a sagittal section or a Ct-Scan digital reconstruction is available. In Heterodontosaurus tucki (Figure 10(a), Norman et al. 2011, Figure 2(b)) and Stegoceras validum (Figure 10(c), Snively and Theodor 2011, Figure 5(b); Bourke et al. 2014, Figure 1 (f)) the ventral margin of the braincase - which follows the inclination of the ventral margin of the laterosphenoid anteriorly - forms an angle of less than $35^{\circ}$ with respect to the basioccipital and basisphenoid (\#122, Figure 10(a,c)). This angle is steeper in Psittacosaurus major (You et al. 2008, Figure 2), Psittacosaurus lujiatunensis (Bullar et al. 2019, fig. $20 \mathrm{~A}$ ) and most other non-marginocephalian taxa (Figure 10 (b,d)).

(2) The cervical centra of Heterodontosaurus tucki (Galton 2014, Figure 4(a)) decrease in length passing throughout the neck. The same occurs between the isolated anterior and posterior cervical centra of Fruitadens haagarorum (Carpenter and Galton 2018, Figure 5(j,1)), and between the cervical centra four and nine of Pachycephalosaurus wyomingensis (Bakker et al. 2006, fig. 10(b), 11(b)). Such a posterior decrease is likely synapomorphic to Pachycephalosauria, but given the absence of complete and articulated necks in derived eupachycephalosaurs we coded these taxa as those keeping the same length of cervical centra throughout the neck (\#201).

(3) The olecranon fossa is shallow to totally absent (\#242, Figure 11) in the humeri of the basal pachycephalosaurs Fruitadens haagarorum and Heterodontosaurus tucki (Figure 11(c,e), Santa Luca 1980; Galton 2014, Figure 9(s,j)), and in the eupachycephalosaurs Stegoceras validum (Figure 11(f), Gilmore 1924, pl. 9.2, p. 34) and Goyocephale lattimorei (Perle et al. 1982, pl. 43.4A). In Wannanosaurus yansiensis, both the olecranon and coronoid fossae are only slightly depressed (Butler and Zhao 2009, Figure 8(d)).

(4) The distal end of the radius is mediolaterally more expanded than the ulna, and distally expands without crossing over the distal end of ulna (\#245) in Heterodontosaurus tucki (Galton 2014, Figure 11(a)), Tianyulong confuciusi (Sereno 2012, fig. 27), Stegoceras validum (Gilmore 1924, Figure 11(c,d)).

(5) The posterior margins of the iliac peduncle of ischium and proximal main axis of the ischial shaft make an angle equal or inferior to $120^{\circ}$ (\#291) in Heterodontosaurus tucki (Figure 8(e), Galton 2014, Figure 12(g)), Prenocephale prenes and Homalocephale calathocercos (Figure 8(f), Maryanska and Osmolska 1974, pl. 25.3B, 29.1).

The first phylogenetic definition of Heterodontosaurinae was proposed by Sereno (2012). This subfamily is defined as the most inclusive group containing Heterodontosaurus tucki but not Tianyulong confuciusi, Fruitadens haagarorum and Echinodon becklesii, and was also recovered as a valid monophyletic clade in this analysis. Heterodontosaurinae share dental synapomorphies: the tooth crowns of the heterodontosaurines H. tucki (Figure 10 (g), Sereno 2012, fig. 55) and Abrictosaurus consors (Sereno 2012, fig. 32, 33) are high, parallel-sided (\#179, \#181) and asymmetrically enamelled (\#171). Note that those characters are also present in ceratopsians (Figure 10(f-h), Yinlong downsi, Han et al. 2015, fig. 21E; Chaoyangsaurus youngi; Zhao et al. 1999, Figure 3(a); Sereno 2010, fig. 1.6A). A posterior maxillary fragment from the Norian of Argentina was referred to cf. Heterodontosaurus sp. (CPBA-V-14091a, Báez and Marsicano 2001). The maxillary crowns of this specimen show clear heterodontosaurine and basal ceratopsian affinities, with the presence of parallel-walled mesiodistal crown edges and the absence of a cinculum. This specimen is possibly associated with a caniniform tooth, which would make it more akin to some kind of basal pachycephalosaur. CPBA-V-14091a is tentatively referred to as Heterodontosaurinae indet.

The non-heterodontosaurine 'heterodontosaurids' Fruitadens haagarorum (Butler et al. 2012), Tianyulong confuciusi (Zheng et al. 2009) and Echinodon becklesii (Owen 1858) share with eupachycephalosaurs the following cranial and postcranial synapomorphies: 

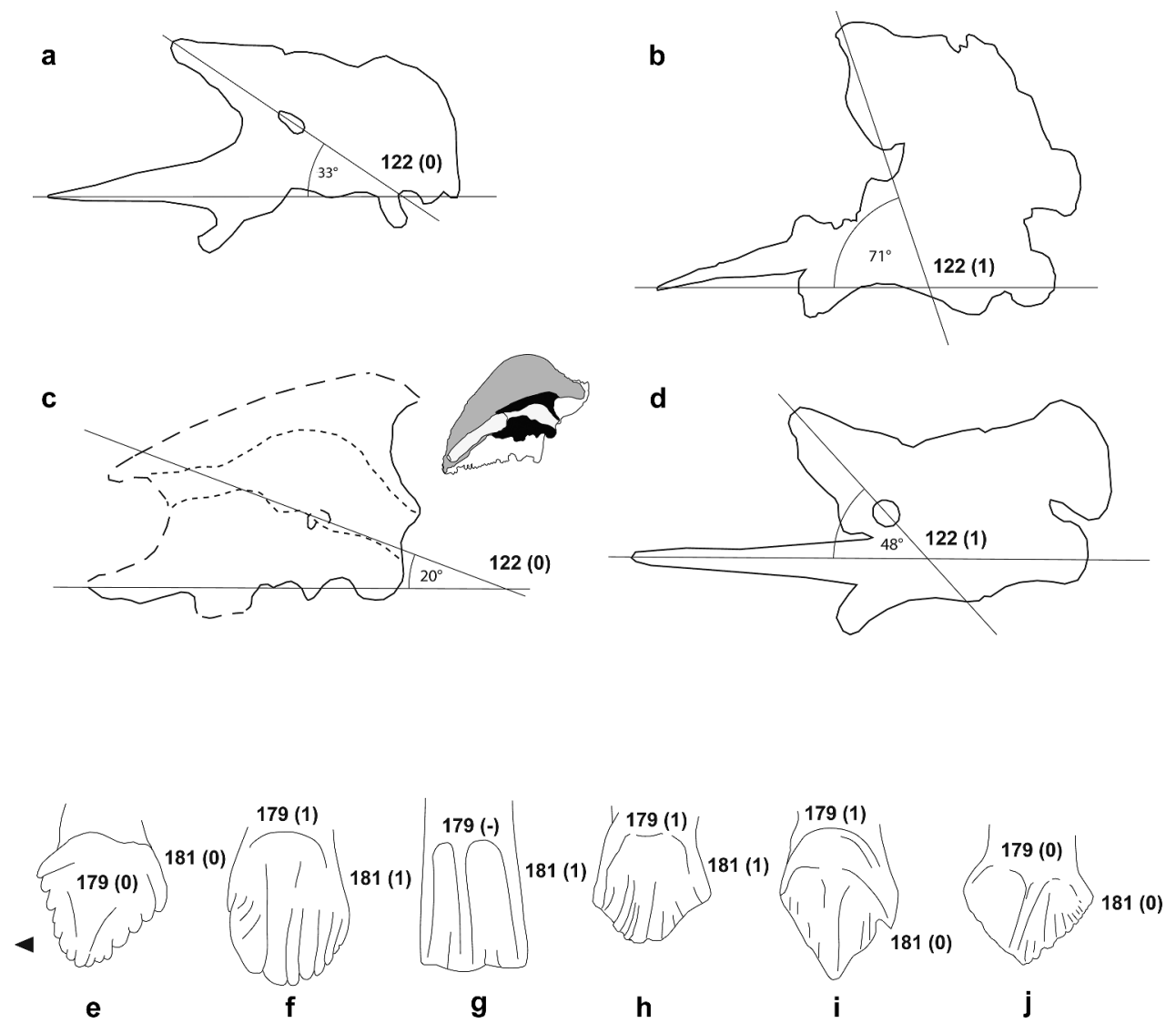

Figure 10. Pachycephalosaurian braincases in lateral view (a-d) and maxillary teeth in labial view (e-j) compared to those of other ornithischians, with: (a) Heterodontosaurus tucki (after Norman et al. 2011); (b) Psittacosaurus major and P. lujiatunensis (after You et al. 2008; Bullar et al. 2019); Stegoceras validum (after Bourke et al. 2014); (e) Hypsilophodon foxii (after Galton 1974a); (e) Lesothosaurus diagnosticus (after Sereno, 1991); (f) Psittacosaurus major (after Sereno 2010); (g) Heterodontosaurus tucki (after Norman et al. 2011); (h) Yinlong downsi (complete reconstruction after Han et al. 2015); (i) Tianyulong confuciusi (after Sereno 2012); (j) Stegoceras validum (after Sues and Galton 1987). Not to scale.

(1) The anterior maxillary tooth row is not medially deflected anteriorly and is aligned with the posterior premaxillary teeth (\#165, Figure 4) in Fruitadens haagarorum (Butler et al. 2012, Figure 7(c,d)), Echinodon becklesii (Sereno 2012, fig. 12, 13), Stegoceras validum, Prenocephale prenes (Figure 4(d), Maryanska and Osmolska 1974, fig. 1A3, C3) and Goyocephale lattimorei (Perle et al. 1982, pl. 41.3).

(2) Echinodon becklesii (Galton 1978, Figure 1(d)) and Tianyulong confuciusi (Zheng et al. 2009) share with the eupachycephalosaurs Wannanosaurus yansiensis (Butler and Zhao 2009, Figure 7(a)) and Stegoceras validum (Figure 6(c), Gilmore 1924, pl. 1; Sues and Galton 1987, Figure 1(a)) the presence of a ventrolaterally extending branch of the coronoid bone that reaches a level ventral to the last dentary teeth (\#151). This feature is absent in Heterodontosaurus tucki (Figure 6(d), Norman et al. 2011, fig. 16).

(3) The teeth of non-heterodontosaurine 'heterodontosaurids' are triangular, 'palmate' $(\# 179, \# 181$, Figure 10(i,j)) and uniformly enamelled on both sides (\#171) (Galton 1978, p. 143; Sereno 2012; Butler et al. 2012), as in eupachycephalosaurs (e.g. Butler and Zhao 2009, Figure 1(b,e), 7(c)).

(4) A continuous tooth wear is not developed in nonheterodontosaurine pachycephalosaurs (\#168, e.g. Butler et al. 2012, p. 11), so their food processing was probably limited to simple puncture crushing of ingesta (Button and Zanno 2020, p. 4).
(5) Sereno (2000, p. 482) had already listed the extremely short forearm - i.e. with a humerus forming less than half the length of the femur - as a pachycephalosaurian characteristic (\#233, Figure 11(f)). However, extreme shortening of the forelimb was also found in Tianyulong confuciusi (Zheng et al. 2009), so this character might, in fact, characterise nonheterodontosaurine pachycephalosaurs.

(6) The postpubis of Tianyulong confuciusi is extremely reduced (\#286, Zheng et al. 2009, supp. info. p. 5). The only pubis known in a eupachycephalosaur so far is that of Homalocephale calathocercos. Although it is unfortunately broken, its preserved portion indicates that its postpubis might have been strongly reduced and splint-like (Maryanska and Osmolska 1974, Figure 5(a), pl. 29.2).

(7) The distal fibular end of Tianyulong confuciusi (Zheng et al. 2009 , p. 6) and Stegoceras validum (the only pachycephalosaur preserving a fibula, cf. Gilmore 1924, pl. 11.2) is splintlike (\#317).

\section{Ornithopod relationships}

\section{An early ornithopod radiation consistent with the fossil record} The dryomorph Callovosaurus leedsi, from the Callovian of England (Ruiz-Omeñaca et al. 2007), has long been regarded as the oldest ornithopod. Other dryosaurids are represented in the Late Jurassic Morrison Formation of United States (e.g. Carpenter 


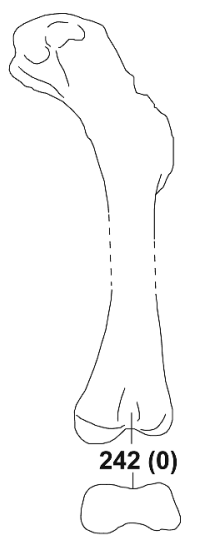

a

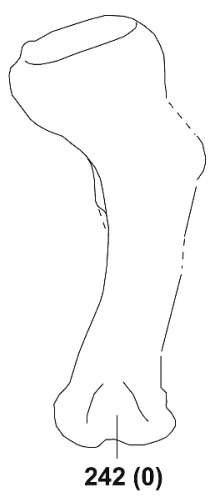

b

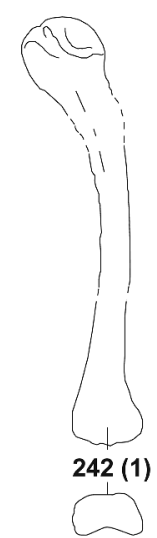

C

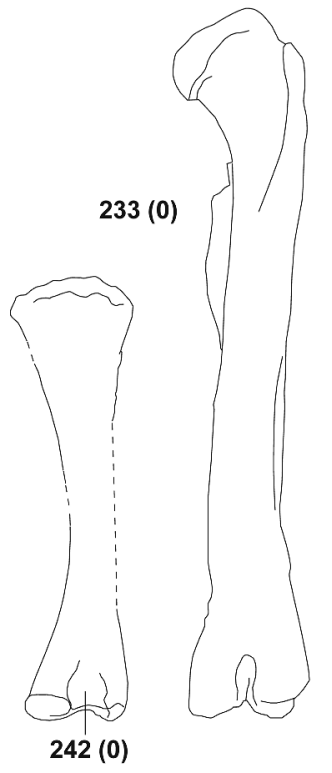

d

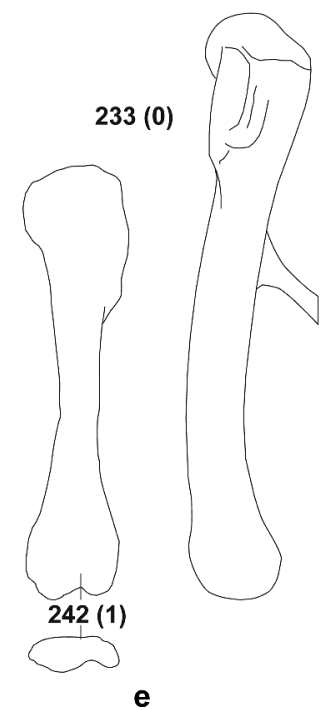

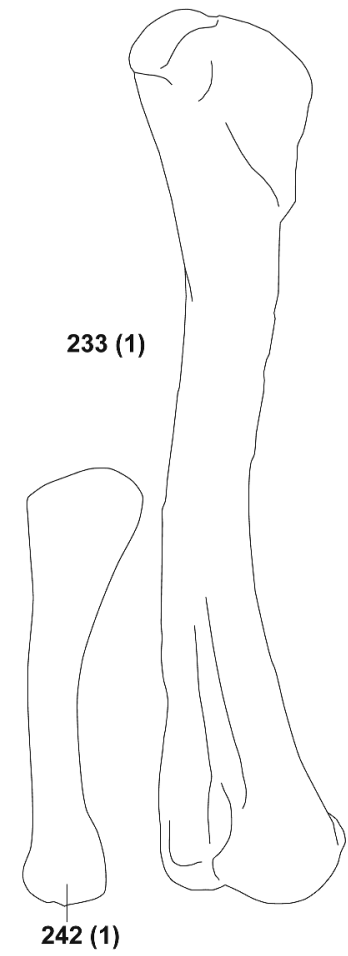

f

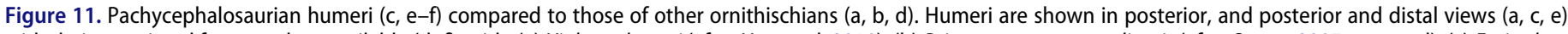

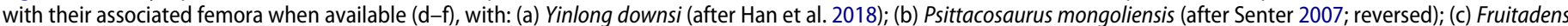

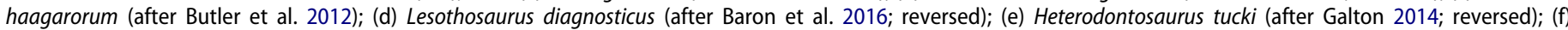

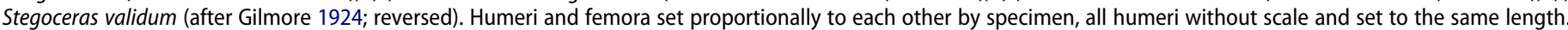

and Galton 2018), Tendaguru Formation of Tanzania (Janensch 1955; Galton 1981) and Lourinhã Formation of Portugal (Rotatori et al. 2020). The Late Jurassic Morrison Formation has also yielded the basal ornithopod Nanosaurus agilis and the Iguanodontia Camptosaurus spp. More primitive ornithopods are mostly recovered later during the Cretaceous. Our setting of 'heterodontosaurids' as basal members of Marginocephalia throws the ornithopod origins back to the earliest stages of the Jurassic (Figure 1). Although increasing the ghost lineage of every non-iguanodontian ornithopods, this result is coherent with the previous contention that the ornithopod radiation was more ancient than the Late Jurassic 'burst' of dryomorph forms (e.g. Weishampel and Heinrich 1992; Mcdonald et al. 2010; Boyd 2015). Kulindadromeus zabaikalicus, from the Bathonian of Siberia (Cincotta et al. 2019) is regarded as a non-clypeodont basal ornithopod (Figure 2). The early age of this taxon is coherent with our new tree topology, and conforts the polarity of ornithopod characters found in earlier works (Butler et al. 2008; Mcdonald et al. 2010; Dieudonné et al. 2016; Rozadilla et al. 2019). The basal position of Kulindadromeus zabaikalicus is partly supported by its retention of a very slender and ventrally directed ischial peduncle of ilium (\#275, Godefroit et al. 2014, fig. S7A). This character is plesiomorphic for neornithischians (e.g. Hexinlusaurus multidens, He and Cai 1984, fig. 17), but is absent in most ornithopods (e.g. N. agilis, Carpenter and Galton, 1018, Fig. 15A; Hypsilophodon foxii, Galton 1974a, fig. 50A).

\section{Problematic basal ornithopod relationships}

Orodrominae was defined by Brown et al. (2013) as 'all thescelosaurids [or ornithopods, cf. Supplemental material 5] more closely 


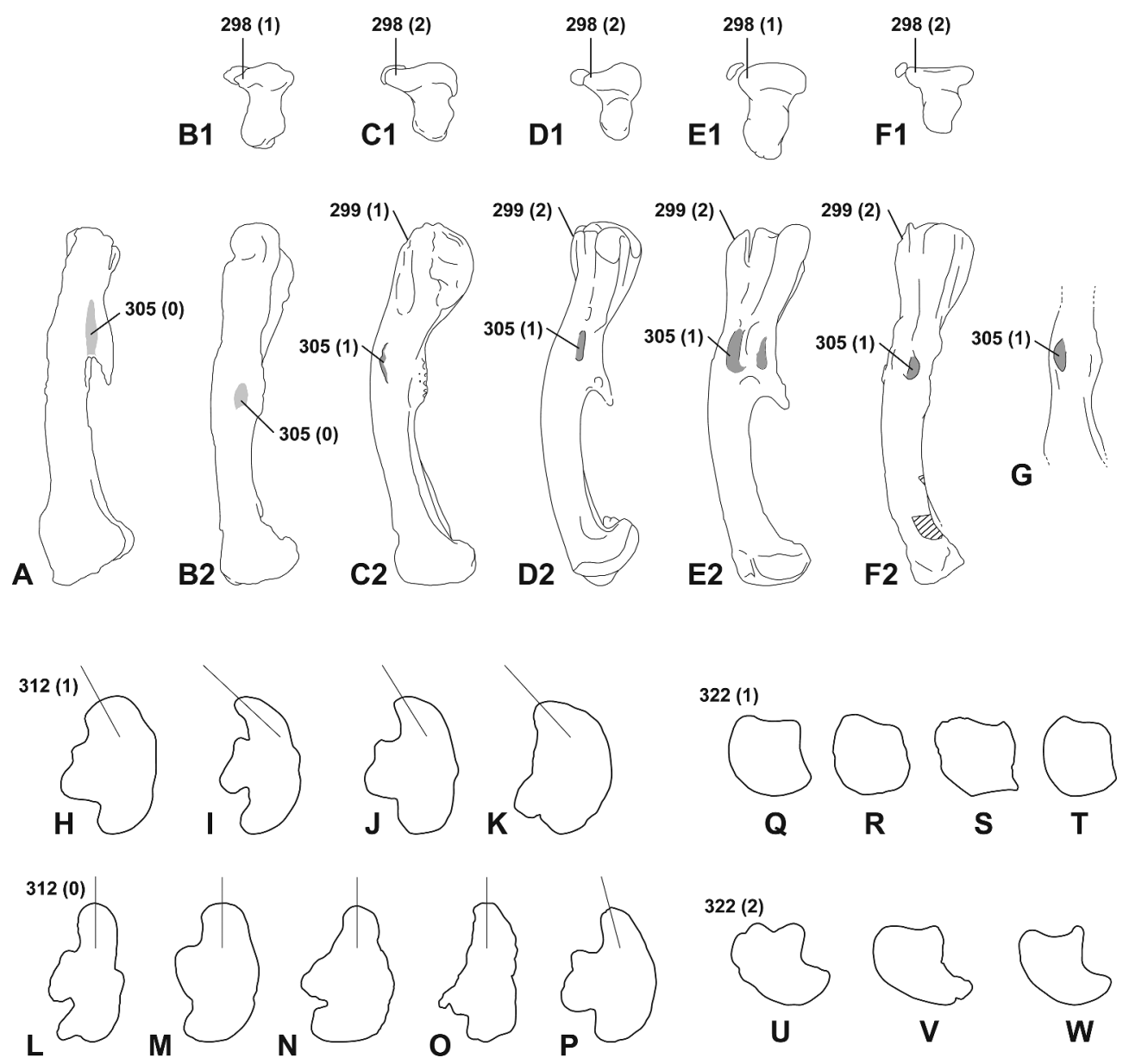

Figure 12. Polarisation of some ornithopodan and basal iguanodontian features on their femora, tibiae and calcanei. Femora in proximal (top) and medial (down) views, with: (a) Convolosaurus marri (after Andrzejewski et al. 2019); (b) Thescelosaurus assiniboiensis (after Brown and Druckenmiller 2011); (c) Kangnasaurus coetzeei (after Cooper 1985); (d) Anabisetia saldiviai (after Coria and Calvo 2002; Cambiaso); (e) Dryosaurus altus (after Carpenter and Galton 2018); (f) Eousdryosaurus nanoallucis (after Escaso et al. 2014); (g) Elrhazosaurus nigeriensis (after Galton, 2009). Tibiae in proximal view with: (h) Hyosilophodon foxii (after Galton 1974a); (i) Camptosaurus aphanoecetes (after Carpenter and Wilson 2008); (j) Dysalotosaurus lettowvorbecki (after Janensch 1955); (k) Draconyx loureiroi (after Mateus and Antunes 2001); (I) T. assiniboiensis (after Brown and Druckenmiller 2011); (m) C. marri (after Andrzejewski et al. 2019); (n) Tenontosaurus tilletti (after Forster 1990); (o) Talenkauen santacrucencis (after Rozadilla et al. 2019); (p) A. saldiviai (after Cambiaso 2007). Calcanei in lateral view, with: (q) H. foxii (after Galton 1974a); (r) C. marri (after Andrzejewski et al. 2019); (s) T. tilletti (after Tennant 2013); (t) T. assiniboiensis (after Brown and Druckenmiller 2011); (u) E. nanohallucis (after Escaso et al. 2014); (v) T. santacrucensis (after Rozadilla et al. 2019); (w) D. lettowvorbecki (after Janensch 1955). Not to scale. N.B.: each bone was subjected to mirror effect whenever necessary so that only right femora, left tibiae and left calcanei are observed for ease of observation.

related to Orodromeus makelai Horner and Weishampel, 1988 than to Thescelosaurus neglectus Gilmore, 1913'. This subfamily was here recovered at the base of Clypeodonta and comprises O. makelai, Zephyrosaurus schaffi and Koreanosaurus boseongensis. Orodrominae is unambiguously supported by the presence of an anterolateral boss on the maxilla (\#31, Scheetz 1999, Figure 5; Sues 1980, Figure 3(a)), and the presence of subparallel dorsoventral margins of the jugal maxillary process (\#86, Scheetz 1999, Figure 4; Sues, 1980, Figure 8). Koreanosaurus boseongensis might bear a closer relationship with $O$. makelai on account of its ventrally keeled cervical vertebrae (\#199, Scheetz, fig. 11-12, Huh et al. 2010, p. 6), but this character is also widespread and found in an array of more derived ornithopod forms, including elasmarians (e.g. Cambiaso 2007, fig. 99). Evidence supporting the orodromine affinity of $K$. boseongensis is rather poor.

Gasparinisaura cincosaltensis was originally defined as a member of Elasmaria (Coria and Salgado 1996; Rozadilla et al. 2016, 2019). G. cincosaltensis actually shares some derived characters with basal iguanodontians and elasmarians, including:
(1) The presence of low and poorly developed cervical neural spines up to their posteriormost cervical vertebrae (\#195; Coria and Salgado 1996; Cambiaso 2007, fig. 56A), as also observed in Dryosaurus altus (Carpenter and Galton 2018, fig. 29B), Camptosaurus dispar (Carpenter and Galton 2018, fig. 14), Orodromeus makelai (Scheetz 1999, Figure 12(a)), and the elasmarians Mahuidacursor lipanglef (Cruzado-Caballero et al. 2019), Talenkauen santacrucensis (Rozadilla et al. 2019, Figure 13(c,d)), Macrogryphosaurus gondwanicus (Calvo et al. 2007, Figure 3) and Anabisetia saldiviai (Cambiaso 2007, p. 215, fig. 99). Cervical neural spines are taller and more prominent in the posterior part of the neck in Tenontosaurus tilletti (Forster 1990, Figure 1), Hypsilophodon foxii (Galton 1974a, fig. 19), Thescelosaurus neglectus (Galton 1974b, pl. 3.3), Convolosaurus marri (Andrzejewski et al. 2019, Figure 13 (b)), and Zalmoxes robustus (Weishampel et al. 2003).

(2) The presence of three manual phalanges on its third finger (\#256; Cambiaso 2007, fig. 65), as in Tenontosaurus tilletti 

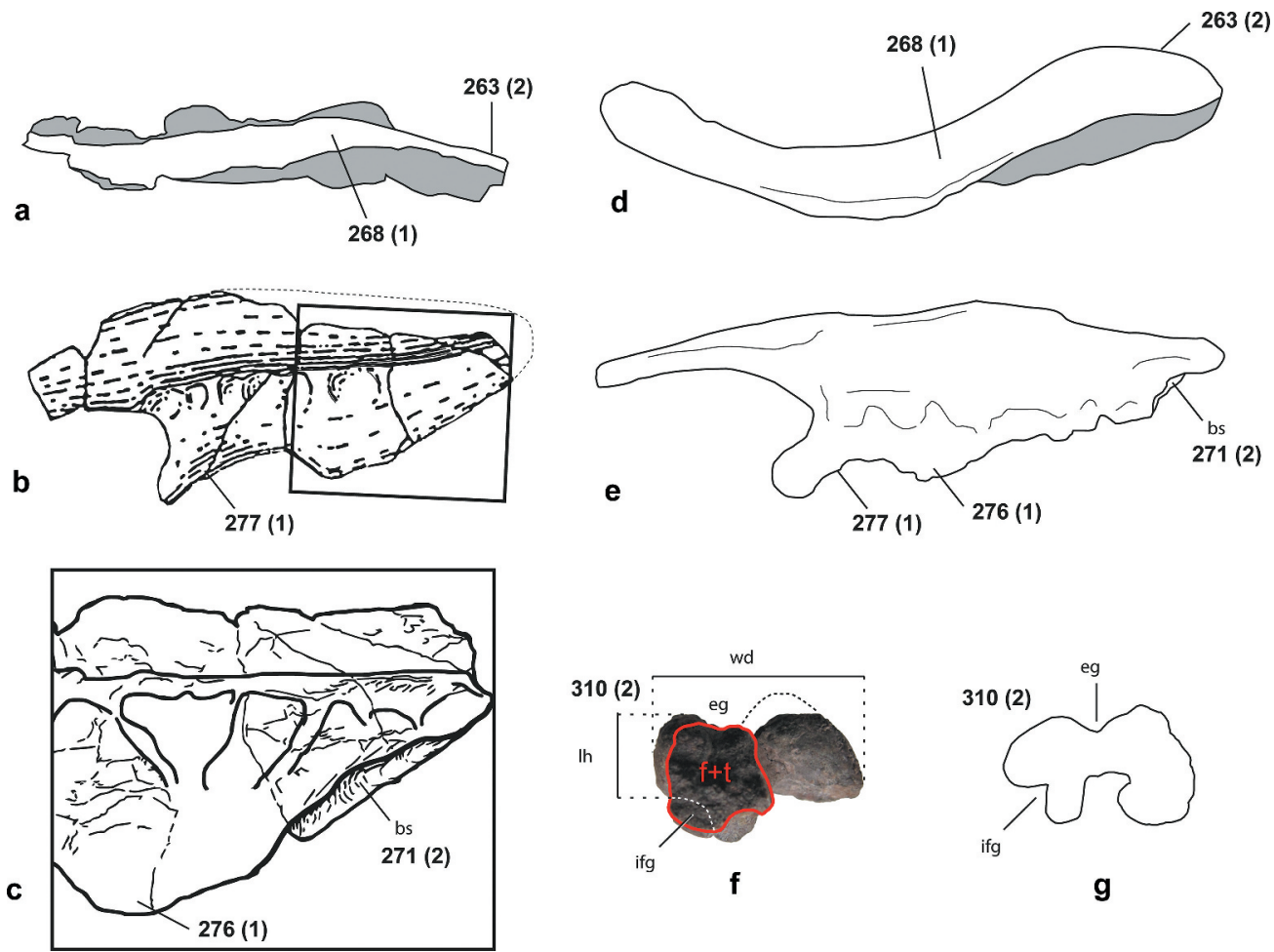

Figure 13. Rhabdodontomorphans features and synapomorphies. (a-c): right ilium of Muttaburrasaurus langdoni (QM F6140) in dorsal view (a) and medial views ((b), original sketch from Bartholomai and Molnar 1981; (c) close-up of postacetabular process); (d-e): left and right ilium of Zalmoxes shqiperorum (after Godefroit et al. 2009) in dorsal (d) and medial ((e), reversed) views; (f) right femur of the Vegagete ornithopod (MDS-VG, 135) in distal view, with fibula and tibia stuck to the distal lateral condyle; (g) right femur of Fostoria dhimbangunmal in distal view (after Bell et al. 2019). N.B.: Line drawing in (a) and (c) were made-up from original photographs of Muttaburrasaurus' ilium (QM F6140). Abbreviations: bs, brevis shelf; eg, extensor groove; $f+t$, fibula and tibia stuck to the distal extremity of femur; ifg, iliofibularis groove; Ih, lateral height without distolateral condylid; wd, distal width. Not to scale.

(Forster 1990, fig. 14B), Camptosaurus dispar (Carpenter and Galton 2018, fig. 23B) and Iguanodon bernissartensis (Norman 1980, fig. 60). More basal ornithopods have usually four phalanges (e.g. Convolosaurus marri, Andrzejewski et al. 2019, fig. 20 ). Note that the phalangeal series of the third finger is incompletely known in dryosaurids, elasmarians or rhabdodontids.

(3) The presence of an extremely elongated greater trochanter of femur (\#298, Salgado et al. 1997, fig. 4.3) is shared with Orodromeus makelai (Scheetz 1999, fig. 28B) but also with Eousdryosaurus nanohallucis (Escaso et al. 2014, Figure 4(e)) and elasmarians (Rozadilla et al. 2016, Figure 3). This character is regarded as an unambiguous synapomorphy of the clade formed by E. nanohallucis and Elasmarians (see below).

Gasparinisaura cincosaltensis is here recovered as a basal, noniguanodontian ornithopod probably because of its retention of an array of basal features such as the lack of extensor groove on its distal femur (Coria and Salgado 1996). Our strict consensus tree recovers $G$. cincosaltensis and Parksosaurus warreni within a monophyletic 'Hypsilophodontidae' (Figure 2), a clade that was for a long time deemed invalid (Galton 1981; Butler et al. 2008). The taxa included within this family form a fragile and dubious grouping, and share the following synapomorphies:

(1) The dorsoventral margins of the dentary converge anteriorly (\#145, Hypsilophodon foxii, Galton 1974a, Figure 10(a); Parksosaurus warreni, 1973, Figure 1; Gasparinisaura cincosaltensis, Coria and Salgado 1996, Figure 2). Note that this apomorphy must be carefully regarded because it was found to be under ontogenetic control in more derived iguanodonts (see Ösi et al. 2012). Note also that although converging anteriorly, the ventral margin of the dentary is straighter in G. cincosaltensis and P. warreni.

(2) The proximolateral margin of the humerus is straight and aligned with the distolateral margin of the humeral shaft (\#239) in Hypsilophodon foxii (Galton 1974a, fig. 38D, 39D) and Gasparinisaura cincosaltensis (Coria and Salgado 1996, Figure 6(a)). This character is also found in Orodromeus makelai (Scheetz 1999, fig. 21A) and dryosaurids (e.g. Galton 1981, fig. 6(b), 7(c)).

(3) The pre-acetabular process of the ilium is smoothly curved anteriorly without any break in slope (\#262, Hypsilophodon foxii, Galton 1974a, fig. 46-48; Gasparinisaura cincosaltensis, Coria and Salgado 1996, Figure 7; Parksosaurus warreni; Parks 1926, Figure 9). This character is plesiomorphic for Ornithopoda and is also found in Nanosaurus agilis (Carpenter and Galton 2018, fig. 15E), Jeholosaurus shangyuanensis (Barrett and Han 2009, Figure 4(c)) and Haya griva (Makovicky et al. 2011, Figure 3).

(4) The second metatarsal is proximally slender with respect to the third metatarsal (\#328) in Hypsilophodon foxii (Galton 1974a, fig. 57H) and Gasparinisaura cincosaltensis (Salgado et al. 1997, fig. 5.5-6). This character is also a synapomorphy of the clade comprising Elasmaria and Eousdryosaurus nanohallucis (cf. below). Although the second metatarsal of $H$. foxii is mediolaterally narrow, it is wider than that of G. cincosaltensis and elasmarians with respect to their third metatarsal (e.g. Rozadilla et al. 2016, Figure 5(a)).

The Argentinian ornithopod Gasparinisura cincosaltensis and the Canadian ornithopod Parksosaurus warreni fall within the 
family Parksosauridae sensu Boyd (2015). Among other characters, they share the following outstanding synapomorphies:

(1) The lower margin of their infratemporal fenestra ends at a level lower than the ventral margin of the orbit (\#4, Galton 1973, Figure 1; Coria and Salgado 1996, Figure 2).

(2) The ventral extent of the jugal wing (consisting in both the posterior process of the jugal and the quadratojugal) contacts the quadrate well above the distal quadrate condyles/ quadratomandibular joint (\#81, Galton 1973, Figure 1; Coria and Salgado 1996, Figure 2).

(3) The quadratojugal is like a ' $\mathrm{T}$ ' rotated clockwise to $90^{\circ}$, with a pronounced angle between its anterior and dorsal branches (\#97, Galton 1973, Figure 1; Coria and Salgado 1996, Figure 2).

(4) Their mid-caudal chevrons are strongly asymmetrically expanded distally (\#218, Parks 1926, pl. 11; Coria and Salgado 1996, fig. 15). Note that this feature is also typically found in Elasmaria (e.g. Cruzado-Caballero et al. 2019) and Convolosaurus marri (Andrzejewski et al. 2019, fig. 17B).

\section{The North American iguanodontian Tenontosaurus and its relatives}

In spite of its larger size, Tenontosaurus has long been interpreted as more similar to a large Hypsilophodon in functional terms than to a small Iguanodon (Dodson 1980; Winkler et al. 1997, p. 346). Calvo et al. (2007) placed Thescelosaurus and Tenontosaurus as a close paraphyletic grouping near the base of Iguanodontia. Tenontosaurus was subsequently placed closer to Dryomorpha (Han et al. 2012; Dieudonné et al. 2016; Bell et al. 2019). Convolosaurus marri is a new ornithopod from the Aptian of the Twin-Mountain Formation in North America (Andrzejewski et al. 2019) and was at first interpreted as very close to Hypsilophodon (Winkler et al. 1988). The present phylogenetic analysis recovers Thescelosaurus, Convolosaurus and Tenontosaurus as successive sister taxa stemming from a long ghost lineage close to the base of Iguanodontia (Figure 2).

The positioning of Tenontosaurus at the base of Iguanodontia (in the sense of Madzia et al. 2018) is supported by its retention of plesiomorphic characters that were lost in other iguanodonts. These characters are as follows:

(1) The posterolateral premaxillary branch of Tenontosaurus tilletti does not contact the prefrontal (\#30, Thomas 2015, Figure 2) as in Hypsilophodon foxii (Galton 1974a, Figure 3). By contrast, this branch contacts the prefrontal in Dryosaurus (Galton 1983, Figure 2(a)), Dysalotosaurus lettowvorbecki (Janensch 1955, Figure 1(a)), Camptosaurus dispar (Gilmore 1909, Figure 2), Iguanodon bernissartensis (Norman 1980, Figure 2) and Muttaburrasaurus langdoni (Bartholomai and Molnar 1981, Figure 1(a)).

(2) The ventral extent of the jugal wing ends only very slightly above the distal quadrate condyles in Tenontosaurus tilletti (\#81, Thomas 2015, Figure 2) and Tenontosaurus dossi (Winkler et al. 1997, Figure 12(b)) as in Hypsilophodon foxii (Galton 1974a, Figure 3). In iguanodonts more derived than Tenontosaurus, the ventral extent of the jugal wing ends well above those distal quadrate condyles (e.g. Muttaburrasaurus langdoni, Bartholomai and Molnar 1981, Figure 1(a); Dysalotosaurus lettowvorbecki; Janensch 1955, Figure 1(a); Iguanodon bernissartensis, Norman 1980, Figure 2; Camptosaurus dispar, Gilmore 1909, Figure 2).

(3) The quadratojugal foramen pierces the central part of the quadratojugal in Tenontosaurus tilletti (\#100, Thomas 2015,
Figure 2) instead of the anterior quadrate margin as in dryosaurids, Camptosaurus dispar (e.g. Carpenter and Lamanna 2015, Figure 13) and Iguanodon bernissartensis (Norman 1980, Figure 2). The quadratojugal of Zalmoxes robustus is devoid of a foramen (Weishampel et al. 2003, Figure 6(c)).

(4) The main body of the quadrate is leant posteriorly (\#102) in Tenontosaurus tilletti (Thomas 2015, Figure 2) and also in more primitive ornithopods such as Hypsilophodon foxii (Galton 1974a, Figure 3). By contrast, it is vertical in other iguanodonts (Zalmoxes robustus, Weishampel et al. 2003, fig. 2(a), 7; dryosaurids and Camptosaurus dispar, Carpenter and Lamanna 2015, Figure 13; Iguanodon bernissartensis, Norman 1980, Figure 2). It is even anteriorly inclined in Muttaburrasaurus langdoni (Bartholomai and Molnar 1981, Figure 1(a)).

(5) The calcaneum of Tenontosaurus tilletti lacks a posterodistal 'lip-like' process (\#322, Figure 12(s), Tennant 2013, fig. 30D) as in the more basal ornithopods Hypsilophodon foxii (Figure 12(q), Galton 1974a, fig. 56A), Convolosaurus marri (Figure 12(r), Andrzejewski et al. 2019, fig. 25B), Thescelosaurus assiniboiensis (Figure 12(t), Brown and Druckenmiller 2011, fig. 21D). The more derived iguanodonians Eousdryosaurus nanohallucis (Figure 12(t), Escaso et al. 2014 Figure 5(m)), Talenkauen santacrucensis (12U, Rozadilla et al. 2019, fig. 27C), Dysalotosaurus lettowvorbecki (Figure 12(v), Janensch 1955, pl. 14.7A) are characterised by a better-developed posterodistal lip-like process. Yueosaurus tiantaiensis is only represented by scarce remains (Zheng et al. 2012). It is recovered as the sistertaxon of Convolosaurus marrii, as both share anteroposteriorly expanded chevrons on their mid caudals (\#218, Andrzejewski et al. 2019, fig. 17A, B). However, this character is relatively widespread and found in Gasparinisaura cincosaltensis (Coria and Salgado 1996), Tenontosaurus tilletti (Forster 1990, Figure 5(a-c)), Macrogryphosaurus gondwanicus (Rozadilla et al. 2020, Figure 9) and Camptosaurus dispar (Gilmore 1909, fig. 19, 20, p. 245).

\section{The basal iguanodontian affinities of Elasmaria}

Rozadilla et al. (2016) already listed synapomorphies that characterise elasmarians, including a globular lateral surface of the greater trochanter (\#301). Moreover, the sternals of Mahuidacursor lipanglef (Cruzado-Caballero et al. 2019) and Macrogryphosaurus gondwanicus (Calvo et al. 2007, Figure 6) markedly differ from those of all other ornithopods. These sternals are right-angled triangles closely appressed to each other along their medial edge and along their paired, anteriorly thinning anterior branches. Their posterolateral process is short and does not expand in a separate rod as in Iguanodon bernissartensis (\#232). In I. bernissartensis the sternals are hatched-shaped with a posterolaterally extending process but with a wider semilunar anteromedial margin (Norman 1980, fig. 56). The sternals of Dryosaurus altus, Camptosaurus dispar, Camptosaurus aphanoecetes, Tenontosaurus tilletti and Tenontosaurus dossi are semi-lunar (Galton 1981, Figure 6(m); Winkler et al. 1997; Dodson and Madsen 1981; Carpenter and Wilson 2008, fig. 18; Carpenter and Galton 2018, fig. $23 \mathrm{~N}$ ). Sternals are unfortunately not known in other iguanodontians, including rhabdodontids.

Iguanodontia Baur (1891) was recently redefined by Madzia et al. (2018) as Iguanodon bernissartensis, Dryosaurus altus, Rhabdodon priscus, Tenontosaurus tilletti, their common ancestors and all of their descendants. According to the present phylogeny and as already proposed by Calvo et al. (2007), Elasmaria are 
therefore members of Iguanodontia, based on the following synapomorphies:

(1) Talenkauen santacrucensis, Tenontosaurus and dryomorphans share a lack of space between adjacent functional teeth and their alveolar border (\#175, Rozadilla et al. 2019, Figure 9; Thomas 2015, fig. 51, 52; Carpenter and Wilson 2008, Figure 5(a,b); Norman 1980, Figure 9).

(2) As in Tenontosaurus tilletti (Thomas 2015, Figure 2), Camptosaurus dispar (Gilmore 1909, Figure 2), Dryosaurus (Galton 1981, pl. 1) and Iguanodon bernissartensis (Norman 1980), the external nares of Talenkauen santacrucensis are enlarged posteriorly so they would have overlapped the maxilla posteriorly (\#22, Rozadilla et al. 2019, Figure 2(c,d)).

(3) A gradual posterior elongation of cervical vertebrae throughout the neck (\#201) is found in Dryosaurus altus (Carpenter and Galton 2018), Camptosaurus dispar (Carpenter and Galton 2018) and elasmarians (CruzadoCaballero et al. 2019). Posterior cervical centra are not specially lengthened in Dysalotosaurus lettowvorbecki (Janensch 1955, pl. 12.10), Iguanodon bernissartensis (Norman 1980, fig. 22) and Tenontosaurus tilletti (Forster 1990, Figure 1) although the latter is characterised by having increased its number of cervicals from 9 to 12 .

\section{Phylogenetic position of Eousdryosaurus}

Escaso et al. (2014) placed Eousdryosaurus nanohallucis - from the Late Jurassic Lourinhã Formation of Portugal - within the dryosaurid clade, as it shares with the dryosaurids Elrhazosaurus nigeriensis (Figure 12(g), Galton and Taquet 1982), Dryosaurus altus and Dysalotosaurus lettowvorbecki (Fig. 12E2, Galton 1981) the presence of a caudifemoralis longus muscle scar that is anteriorly displaced with respect to the fourth trochanter medially (\#305, Fig. 12F2). However, this character is also present in the elasmarians Kangnasaurus coetzeei (Fig. 12C2, Cooper 1985), Anabisetia saldiviai (Fig. 12D2, Coria and Calvo 2002, p. 506, Figure 7(c)) and in the basal camptosaurid Draconyx loureiroi (Mateus and Antunes 2001). This character is clearly absent in more massively built ankylopollexians, such as Camptosaurus aphanoecetes (Carpenter and Wilson 2008, fig. $30 \mathrm{C}, \mathrm{N})$ or Iguanodon bernissartensis (Norman 1980, fig. 68B). The lesser trochanter of E. nanohallucis is high and reaches the upper level of the fourth trochanter (\#299, Fig. 12F2, Escaso et al. 2014, Figure 4), as also observed in dryosaurids (Fig. 12E2, Galton 1981, Figure 13(c), 14 C, I), A. saldiviai (Coria and Calvo 2002, Figure 7), and Valdosaurus canaliculatus (Barrett et al. 2011, pl. 1.4), but not in K. coetzeei (Fig. 12C2, Cooper 1985, Figure 12(a)), Morrosaurus antarcticus (Rozadilla et al. 2016, Figure 2(a)) and E. nigeriensis (Galton and Taquet 1982). Camptosaurus aphanoecetes is polymorphic for this character (Carpenter and Wilson 2008, fig. 30). In dorsal view, the cnemial crest of the tibia of E. nanohallucis projects straight anteriorly (\#312, Escaso et al. 2014, Figure $4(\mathrm{~m})$ ), as in A. saldiviai, M. antarcticus (Figure 12(p), Cambiaso 2007, fig. 49D, 117E), T. santacrucensis (Figure 12(o), Rozadilla et al. 2019, fig. 24E), but also other iguanodontians such as $V$. canaliculatus (Barrett et al. 2011, Figure 7(b,h)), Convolosaurus marri (Figure 12(m), Andrzejewski et al. 2019, fig. 24I) and Tenontosaurus tilletti (Figure 12(n), Forster 1990, fig. 20B). By contrast, the cnemial crest is laterally deflected in D. altus (Galton 1981, fig. 16E), D. lettowvorbecki (Figure 12(j), Janensch 1955, pl. 14.3C), D. loureiroi (Figure 12(k), Mateus and Antunes 2001, Figure 8), and ankylopollexians such as C. aphanoecetes (Figure 12(i), Carpenter and Wilson 2008, fig. 31E). We suspect that such a lateral deflection of the cnemial crest is plesiomorphic within
Ornithopoda, as it is also present in Hypsilophodon foxii (Figure 12(h), Galton 1974a, fig. 56E), and Nanosaurus agilis (Galton and Jensen 1973, Figure 5(b-c)). E. nanohallucis retains the plesiomorphic presence of a proximal articular surface on its first metatarsal (\#335, Escaso pers. comm.), a feature that is shared with T. santacrucensis (Rozadilla et al. 2019, fig. S7E), A. saldiviai (Cambiaso 2007, fig. 120B), Gasparinisaura cincosaltensis (Cambiaso 2007, fig. 76C), but that had been lost in rhabdodontids (Dieudonné et al. 2016) and ankylopollexians (e.g. C. dispar, Carpenter and Galton 2018, fig. 26GG).

In the present phylogeny, Eousdryosaurus nanohallucis is the sister-taxon of Elasmaria based on the following synapomorphies:

(1) The greater trochanter of the femur is anteriorly elongated (\#298). This character is found in Eousdryosaurus nanohallucis (Fig. 12F1, Escaso et al. 2014, Figure 4(e)), Morrosaurus antarcticus, Anabisetia saldiviai and Kangnasaurus coetzeei (Fig. 12C2, D2, Rozadilla et al. 2016, Figure 3(a-b,g)).

(2) The lateral surface of its second metatarsal is flat to broadly concave for resting against the third metatarsal (\#327, Escaso et al. 2014, Figure 6), a primitive condition resulting from a secondary reversion in Elasmaria (e.g. Kangnasaurus coetzeei, Cooper 1985, fig. 19; Morrosaurus antarcticus, Cambiaso 2007, fig. 52A). A proximal lateral 'step' is observed in the second metatarsal of dryomorphs (e.g. Herne et al. 2018, fig. 32H-I) but also in that of the more basal iguanodontian Tenontosaurus tilletti (Forster 1990, fig. 22A). However, the position of Eousdryosaurus nanohallucis as rooting Elasmaria remains weakly supported and would certainly be reassessed with the discovery of more complete material.

\section{A re-appraisal of Rhabdodontomorpha}

Bartholomai and Molnar (1981) proposed a close relationship of Muttaburrasaurus langdoni with ankylopollexians based on the presence of a 'cushion-shaped' ulnare in the latter (\#247). Dieudonné et al. (2016) included M. langdoni and rhabdodontids within a node-based Rhabdodontomorpha. Recently, Herne et al. (2019) and Bell et al. (2019) again suggested a closer affinity of M. langdoni with basal ankylopollexians than with rhabdodontids, thus querying the validity of Rhabdodontomorpha. This clade was redefined by Madzia et al. (2020) as the least inclusive group comprising Rhabdodon priscus but not Iguanodon bernissartensis, and find M. langdoni within Ankylopollexia.

Indeed, However, the present phylogenetic analysis supports the monophyly of Rhabdodontomorpha, which we regard as a nodebased clade following its original definition (Dieudonné et al. 2016). Rhabdodontomorpha is supported by the following synapomorphies:

(1) The outline of the dorsal iliac margin is sigmoidal in dorsal view, with the postacetabular process deflected medialward and the pre-acetabular process deflected laterally (\#263, Figure 13(a,d), Weishampel et al. 2003, fig. 22C; Godefroit et al. 2009, Figure 13(a-b), 18C).

(2) As previously mentioned (Dieudonné et al. 2016), the dorsal iliac margin of Muttaburrasaurus langdoni is mediolaterally broader and swollen from above the ischiac peduncle anteriorly (\#268, Figure 13(a)) and that of Zalmoxes robustus and Zalmoxes shqiperorum is mediolaterally swollen from above the postacetabular process all along (Figure 13(d), Weishampel et al. 2003, fig. 22C; Godefroit et al. 2009, Figure 13(a,b)). Such a broadening over the dorsal iliac margin is quite unique among ornithopods. 
(3) The brevis shelf was never described in any rhabdodontomorph. Yet, Muttaburrasaurus langdoni (Figure 13(c)) and Zalmoxes shqiperorum (Figure 13(e), Godefroit et al. 2009, fig. 18B) share the presence of a weak, dorsally convex ridge on the ventromedial side of their postacetabular process. We refer this ridge to a vestigial brevis shelf. Such a weak ridge might characterise the brevis shelf of every rhabdodontomorphs (\#271).

(4) The ischiac peduncle of the ilium is lenticular and uniquely anteroposteriorly long (\#276) in Muttaburrasaurus langdoni (Figure 13(c)) and rhabdodontids (Figure 13(e); Weishampel et al. 2003, fig. 22A; Godefroit et al. 2009, fig. 18A-D).

(5) The acetabulum is noticeably low (\#277) in Muttaburrasaurus langdoni (Figure 13(b), Bartholomai and Molnar 1981, Figure 8(a)), Zalmoxes shqiperorum (Figure 13 (e), Godefroit et al. 2009, fig. 18A-B), Zalmoxes robustus (Weishampel et al. 2003, fig. 22A).

The Rhabdodontidae as defined by Sereno (2005) is more inclusive than Rhabdodontomorpha as defined by Dieudonné et al. (2016). We stick to the original node-based definition of Rhabdodontidae (Weishampel et al. 2003). The Vegagete ornithopod becomes the closest outgroup of this family. The polytomy between Fostoria dhimbangunmal, the Vegagete ornithopod and rhabdodontids in the strict consensus (Figure 2) is likely an artefact related to the skeletal incompleteness of these taxa. Indeed, most features characterising the Vegagete ornithopod and rhabdodontids remain unknown in F. dhimbangunmal. F. dhimbangunmal only shares the following synapomorphies with the Vegagete ornithopod and the rhabdodontid lineage:

(1) A nearly vertical suture between its supraoccipital and opisthotics (\#112, Bell et al. 2019, p. 6; Weishampel et al. 2003, Figure 10(b); Godefroit et al. 2009, Figure 4(c,d)); this character is not clearly defined in Muttaburrasaurus langdoni.

(2) The length of the distolateral condyle on the distal extremity of femur (not accounting for its posterolateral condylid) is less than $40 \%$ the total distal width of the femur (\#310) in Fostoria dhimbangunmal (Figure 13(g), Bell et al. 2019, Figure 8(e)), the Vegagete ornithopod (Figure 13(f), Dieudonné et al. 2016, fig. 8D2, E2)and all rhabdodontids (Dieudonné et al. 2016, fig. 16). In Muttaburrasaurus langdoni (Bartholomai and Molnar 1981, Figure 9(g)), Tenontosaurus tilletti (Forster 1990, fig. 19) and Camptosaurus aphanoecetes (Carpenter and Wilson 2008, fig. 30E) the distal femora are mediolaterally broad although their length-to-breadth proportions slightly exceeds $40 \%$.

The templeton test (Supplemental material 6) suggests that Muttaburrasaurus langdoni bears some affinities with basal ankylopollexians, as was previously argued by Herne et al. (2019) and Bell et al. (2019). However, the monophyly of Rhabdodontomorpha is supported by the present analysis. An alternative positioning of the whole clade closer to the base of Ankylopollexia would require the discovery of more common, overlapping skeletal elements between European rhabdodontomorphs and ankylopollexians.

\section{Conclusion}

The present phylogenetic analysis recovers 'heterodontosaurids' as basal members of Marginocephalia, forming a paraphyletic lineage at the base of Pachycephalosauria. This hypothesis significantly reduces the ghost lineage for Pachycephalosauria and pulls the ornithopod origins back to the earliest stages of the Jurassic. Basal ornithopod relationships remain poorly resolved. Tenontosaurus is found as the basalmost iguanodontian. Eousdryosaurus nanohallucis, previously included within the dryosaurid clade, is here regarded as the sister-taxon of Elasmaria. The monophyly of Rhabdodontomorpha, in a position more derived than Tenontosaurus, is supported by the present analysis.

\section{Acknowledgments}

We are grateful to Catherine Forster, Phil Senter, Matthew Herne, Fernando Escaso for their helpful answers to questions concerning material in their care. Special thanks go to Matthew Herne and Fidel Torcida Fernández-Baldor for sharing important photographs and to Miguel Moreno for his invaluable advices on how to proceed with phylogenetic methods. We are particularly grateful to Matt Baron for his careful revision of an earlier version of this paper. More personally, we thank all the people who helped directly or indirectly, and who provided unconditional support, help and accommodation facilities through the long years of data matrix construction and revision (Ferrán and Alba, Cope and Silvia, Fidel, Geoffroy and his family, first author's family). Financial support has been partially provided by the Spanish Ministerio de Ciencia e Innovación and the European Regional Development Fund (CGL2017-85038-P), by the Agencia Nacional de Promoción Científica y Técnica (PICT 2016-0491), by the Universidad Nacional de Río Negro (PI 40-A-737).

\section{Disclosure statement}

No potential conflict of interest was reported by the authors.

\section{Funding}

This work was supported by the Ministerio de Ciencia e Innovación and the European Regional Development Fund [CGL2017-85038-P]; the Agencia Nacional de Promoción Científica y Técnica [PICT 2016-0491].

\section{ORCID}

P. -E. Dieudonné (iD http://orcid.org/0000-0001-8283-7514

P. Cruzado-Caballero (iD) http://orcid.org/0000-0002-5819-8254

\section{References}

Andrzejewski KA, Winkler DA, Jacobs LL. 2019. A new basal ornithopod (Dinosauria: Ornithischia) from the Early Cretaceous of Texas. PLoS ONE. 14:1-44.

Báez AM, Marsicano CA. 2001. A heterodontosaurid ornithischian dinosaur from the Upper Triassic of Patagonia. Ameghiniana. 38:271-279.

Bakker RT, Galton PM. 1974. Dinosaur monophyly and a new class of vertebrates. Nature. 248:168-172.

Bakker RT, Sullivan RM, Porter V, Larson P, Saulsbury SJ. 2006. Dracorex hogwartsia, n. gen. n. sp., a spiked, flat-headed pachycephalosaurid dinosaur from the Upper Cretaceous Hell Creek Formation of South Dakota. N M Mus Nat Hist Sci Bull. 35:331-345.

Baron MG, Barrett PM. 2017. A dinosaur missing-link? Chilesaurus and the early evolution of ornithischian dinosaurs. Biol Lett. 13(8):20170220.

Baron MG, Norman DB, Barrett PM. 2016. Postcranial anatomy of Lesothosaurus diagnosticus (Dinosauria: Ornithischia) from the Lower Jurassic of southern Africa : implications for basal ornithischian taxonomy and systematics. Zool J Linn Soc. 179:125-168.

Baron MG, Norman DB, Barrett PM. 2017. A new hypothesis of dinosaur relationships and early dinosaur evolution. Nature. 543:501-506.

Barrett PM, Butler RJ, Mundil R, Scheyer TM, Irmis RB, Sanchez-Villagra MR. 2014. A palaeoequatorial ornithischian and new constraints on early dinosaur diversification. Proc R Soc B Biol Sci. 281:20141147.

Barrett PM, Butler RJ, Twitchett RJ, Hutt S. 2011. New material of Valdosaurus canaliculatus (Ornithischia, Ornithopoda) from the Lower Cretaceous of southern England. Spec Pap Palaeontol. 86:131-163.

Barrett PM, Han F-L. 2009. Cranial anatomy of Jeholosaurus shangyuanensis (Dinosauria: Ornithischia) from the Early Cretaceous of China. Zootaxa, 2072, 31-55. 1 doi:10.11646/zootaxa.2072.1

Barrett PM, Maidment SCR. 2011. The locomotor musculature of basal ornithischian dinosaurs. J Vertebr Paleontol. 31:1265-1391. 
Bartholomai A, Molnar RE. 1981. Muttaburrasaurus, a new iguanodontid (Ornithischia: Ornithopoda) dinosaur from the Lower Cretaceous of Queensland. Mem Queensl Mus. 20:319-349.

Baur G. 1891. Remarks on the reptiles generally called Dinosauria. Am Nat. 25 (293):434-454.

Becerra MG, Pol D. 2020. The enamel microstructure of Manidens condorensis: new hypotheses on the ancestral state and evolution of enamel in Ornithischia. Acta Palaeontol Pol. 65:59-70.

Bell PR, Brougham T, Herne MC, Frauenfelder T, Smith ET. 2019. Fostoria dhimbangunmal, gen. et sp. nov., a new iguanodontian (Dinosauria, Ornithopoda) from the mid-Cretaceous of Lightning Ridge, New South Wales, Australia. J Vertebr Paleontol. 39:e1564757.

Bell PR, Herne MC, Brougham T, Smith ET. 2018. Ornithopod diversity in the Griman Creek Formation (Cenomanian), New South Wales, Australia. PeerJ. 6:e6008.

Bourke JM, Ruger Porter WM, Ridgely RC, Lyson TR, Schachner ER, Bell PR, Witmer LM. 2014. Breathing life into dinosaurs: tackling challenges of soft-tissue restoration and nasal airflow in extinct species. Anat Rec. 297:2148-2186.

Boyd CA. 2015. The systematic relationships and biogeographic history of ornithischian dinosaurs. PeerJ. 3:1-62.

Brown B, Schlaikjer EM. 1940. The structure and relationships of Protoceratops. Ann N Y Acad Sci. 40:133-266.

Brown B, Schlaikjer EM. 1943. A study of the troödont dinosaurs, with the description of a new genus and four new species. Bull Am Mus Nat Hist. $82: 115-150$.

Brown CM, Druckenmiller P. 2011. Basal ornithopod (Dinosauria: Ornithischia) teeth from the Prince Creek Formation (Early Maastrichtian) of Alaska. Can J Earth Sci. 48:1342-1354.

Brown CM, Evans DC, Ryan MJ, Russell AP. 2013. New data on the diversity and abundance of small-bodied ornithopods (Dinosauria, Ornithischia) from the Belly River Group (Campanian) of Alberta. J Vertebr Paleontol. 33:495-520.

Bullar CM, Zhao Q, Benton MJ, Ryan MJ. 2019. Ontogenetic braincase development in Psittacosaurus lujiatunensis (Dinosauria: Ceratopsia) using micro-computed tomography. Peerj. 7:e7217.

Butler RJ. 2010. The anatomy of the basal ornithischian dinosaur Eocursor parvus from the lower Elliot Formation (Late Triassic) of South Africa. Zool J Linn Soc. 160:648-684.

Butler RJ, Porro LB, Galton PM, Chiappe LM. 2012. Anatomy and cranial functional morphology of the small-bodied dinosaur Fruitadens haagarorum from the Upper Jurassic of the USA. PLoS ONE. 7:e31556.

Butler RJ, Smith RMH, Norman DB. 2007. A primitive ornithischian dinosaur from the Late Triassic of South Africa, and the early evolution and diversification of Ornithischia. Proc R Soc London Ser B. 274:2041-2046.

Butler RJ, Sullivan RM. 2009. The phylogenetic position of the ornithischian dinosaur Stenopelix valdensis from the Lower Cretaceous of Germany and the early fossil record of Pachycephalosauria. Acta Palaeontol Pol. 54:21-34.

Butler RJ, Sullivan RM, Upchurch P, Norman DB. 2008. The phylogeny of the ornithischian dinosaurs. J Syst Palaeontol. 6:1-40.

Butler RJ, Zhao Q. 2009. The small-bodied ornithischian dinosaurs Micropachycephalosaurus hongtuyanensis and Wannanosaurus yansiensis from the Late Cretaceous of China. Cretac Res. 30:63-77.

Button DJ, Zanno L. 2020. Repeated evolution of divergent modes of herbivory in non-avian dinosaurs. Curr Biol. 30:158-168.

Calvo J, Porfiri J, Novas F. 2007. Discovery of a new ornithopod dinosaur from the Portezuelo Formation (Upper Cretaceous), Neuquén, Patagonia, Argentina. Arq Mus Nac. 65:471-483.

Cambiaso AV. 2007. Los ornitópodos e iguanodontes basales (Dinosauria Ornithischia) del Cretácico de Argentina y Antártida [The ornithopods and basal iguanodonts (Dinosauria, Ornithischia) from the Cretaceous of Argentina and the Antarctic]. Unpublished PhD thesis, Universidad de Buenos Aires, Facultad de Ciencias Exactas y Naturales; p. 410. Spanish.

Carpenter K, Galton PM. 2018. A photo documentation of bipedal ornithischian dinosaurs from the Upper Jurassic Morrison Formation, USA. Geol Intermountain West. 5:167-207.

Carpenter K, Lamanna MC. 2015. The braincase assigned to the ornithopod dinosaur Uteodon McDonald, 2011, reassigned to Dryosaurus Marsh, 1894: implications for Iguanodontian morphology and taxonomy. Ann Carnegie Mus. 83:149-165.

Carpenter K, Wilson Y. 2008. A new species of Camptosaurus (Ornithopoda: Dinosauria) from the Morrison formation (Upper Jurassic) of Dinosaur National Monument, Utah, and biomechanical analysis of its forelimb. Ann Carnegie Mus. 76:227-263.

Charig AJ. 1972. The evolution of the archosaur pelvis and hindlimb: an explanation in functional terms. In: KA J, TS K, editors. Studies in vertebrate evolution: essays presented to Dr. F. R. Parrington, F.R.S. Edinburgh: Oliver and Boyd; p. 121-155.
Cincotta A, Pestchevitskaya EB, Sinitsa SM, Markevich VS, Debaille V, Reshetova SA, Mashchuk IM, Frolov AO, Gerdes A, Yans J, et al. 2019. The rise of feathered dinosaurs: Kulindadromeus zabaikalicus, the oldest dinosaur with 'feather-like' structures. PeerJ. 7:e6239.

Cohen KM, Finney SC, Gibbard PL, Fan J-X. 2013, updated. The ICS International Chronostratigraphic Chart. Episode. 36:199-204.

Cooper MR. 1985. A revision of the ornithischian dinosaur Kangnasaurus coetzeei Haughton, with a classification of the Ornithischia. Ann S Afr Mus. 95:281-317.

Coria RA, Calvo JO. 2002. A new Iguanodontian Ornithopod from Neuquen Basin, Patagonia, Argentina. J Vertebr Paleontol. 22:503-509.

Coria RA, Salgado L. 1996. A basal iguanodontian (Ornithischia, Ornithopoda) from the Late Cretaceous of South America. J Vertebr Paleontol. 16:445-457.

Cruzado-Caballero P, Gasca JM, Filippi LS, Cerda I, Garrido AC. 2019. A new ornithopod dinosaur from the Santonian of Northern Patagonia (Rincón de los Sauces, Argentina). Cretac Res. 98:211-229.

Dieudonné P-E, Tortosa T, Torcida Fernandez Baldor F, Canudo JI, DiazMartinez I. 2016. An unexpected early rhabdodontid from Europe (Lower Cretaceous of Salas de los Infantes, Burgos Province, Spain) and a re-examination of basal iguanodontian relationships. PLoS ONE. 11:e0156251.

Dodson P. 1980. Comparative osteology of the american ornithopods Camptosaurus and Tenontosaurus. Mém Soc Géol Fr. 139:81-85.

Dodson P, Madsen JH. 1981. On the sternum of Camptosaurus. J Paleontol. 55:109-112.

Dong Z, Azuma Y. 1997. On a primitive neoceratopsian from the Early Cretaceous of China. Sino-Japanese Silk Road Dinosaur Expedition. Beijing: China Ocean Press; p. 68-89.

Escaso F, Ortega F, Dantas P, Malafaia E, Silva B, Gasulla JM, Mocho P, Narvaez I, Sanz JL. 2014. A new dryosaurid ornithopod (Dinosauria, Ornithischia) from the Late Jurassic of Portugal. J Vertebr Paleontol. 34:1102-1112.

Felsenstein J. 1978. Cases in which parsimony or compatibility methods will be positively misleading. Syst Zool. 27:401-410.

Felsenstein J. 2004. Inferring phylogenies. Sunderland (Massachusetts): Sinauer associates, Inc; p. 664.

FL, Rozadilla S. 2017. Phylogenetic reassessment of Pisanosaurus mertii Casamiquela, 1967, a basal dinosauriform from the Late Triassic of Argentina. J Syst Palaeontol. 16:853-879.

Forster CA. 1990. The postcranial skeleton of the ornithopod dinosaur Tenontosaurus tilletti. J Vertebr Paleontol. 10:273-294.

Galton PM. 1970. Ornithischian dinosaurs and the origin of birds. Evolution. 24:448-462.

Galton PM. 1973. Redescription of the skull and mandible of Parksosaurus from the Late Cretaceous with comments on the family Hypsilophodontidae (Ornithischia). Life Sci Contrib R Ont Mus. 89:1-21.

Galton PM 1974a. The ornithischian dinosaur Hypsilophodon from the Wealden of the Isle of Wight. Bulletin of the British Museum. Natural History. Geology Series, 25, 1-152.

Galton PM. 1974b. Notes on Thescelosaurus, a conservative ornithopod dinosaur from the Upper Cretaceous of North America, with comments on ornithopod classification. J Paleontol. 48:1048-1067.

Galton PM. 1978. Fabrosauridae, the basal family of ornithischian dinosaurs (Reptilia: Ornithopoda). Paläontol Z. 52:138.

Galton PM. 1981. Dryosaurus, a hypsilophodontid dinosaur from the Upper Jurassic of North America and Africa; postcranial skeleton. Palaeontol Z. 55:271-312.

Galton PM. 1983. The cranial anatomy of Dryosaurus, a hypsilophodontid dinosaur from the Upper Jurassic of North America and East Africa, with a review of hypsilophodontids from the Upper Jurassic of North America. Geol Palaeontol. 17:207-43.

Galton PM. 2009. Notes on Neocomian (Lower Cretaceous) ornithopod dinosaurs from England - Hypsilophodon, Valdosaurus, 'Camptosaurus', 'Iguanodon' - and referred specimens from Romania and elsewhere. Rev Paléobiol. 28:211-73.

Galton PM. 2014. Notes on the postcranial anatomy of the heterodontosaurid dinosaur Heterodontosaurus tucki, a basal ornithischian from the Lower Jurassic of South Africa. Rev Paléobiol. 33:97-141.

Galton PM, Jensen JA. 1973. Skeleton of a hypsilophodontid dinosaur (Nanosaurus (?) rex) from the Upper Jurassic of Utah. Brigham Young Univ Res Stud Geology Series. 20:137-157.

Galton PM, Taquet P. 1982. Valdosaurus, a hypsilophodontid dinosaur from the Lower Cretaceous of Europe and Africa. Geobios. 15:147-159.

Gasca JM, Canudo J-I, Moreno Azanza M. 2014. On the diversity of Iberian iguanodont dinosaurs: new fossils from the lower Barremian, Teruel province, Spain. Cretac Res. 50:264-272.

Gauthier JA. 1986. Saurischian monophyly and the origin of birds. Mem California Acad Sci. 8:1-55 
Gilmore CW. 1909. Osteology of the Jurassic reptile Camptosaurus, with a revision of the species of the genus, and description of two new species. Proc U S Natl Mus. 36:197-332.

Gilmore CW. 1913. A new dinosaur from the Lance Formation of Wyoming Smithson Misc Collect. 61:1-5.

Gilmore CW. 1924. On Troodon validus, an Orthopodous Dinosaur from the Belly River Cretaceous of Alberta, Canada. Univ Alberta Press. 1:1-58.

Godefroit P, Codrea V, Weishampel DB. 2009. Osteology of Zalmoxes shqiperorum (Dinosauria, Ornithopoda), based on new specimens from the Upper Cretaceous of Nalat-Vad (Romania). Geodiversitas. 31:525-553.

Godefroit P, Sinitsa SM, Dhouailly D, Bolotsky YL, Sizov AV, Mcnamara ME, Benton MJ, Spagna P. 2014. A Jurassic ornithischian dinosaur from Siberia with both feathers and scales. Science. 345:451-455.

Goloboff P, Catalano S. 2016. TNT, version 1.5, with a full implementation of phylogenetic morphometrics. Cladistics. doi:10.1111/cla.12160.

Goloboff P, Farris J, Nixon K. 2008. TNT, a free program for phylogenetic analysis. Cladistic. 24:774-786.

Hailu Y, Dodson P. 2004. Basal ceratopsia. In: Weishampel DB, Dodson P, Osmolska H, editors. The dinosauria. 2nd ed. Berkeley: University of California Press; p. 478-493.

Han F-L, Barrett PM, Butler RJ, Xu X. 2012. Postcranial anatomy of Jeholosaurus shangyuanensis (Dinosauria, Ornithischia) from the Lower Cretaceous Yixian Formation of China. J Vertebr Paleontol. 32:1370-1395.

Han F-L, Forster CA, Clark JM, Xu X. 2015. Cranial anatomy of Yinlong downsi (Ornithischia: Ceratopsia) from the Upper Jurassic Shishugou Formation of Xinjiang, China. J Vertebr Paleontol. 36:e1029579.

Han F-L, Forster CA, Xu X, Clark JM. 2018. Postcranial anatomy of Yinlong downsi (Dinosauria: Ceratopsia) from the Upper Jurassic Shishugou Formation of China and the phylogeny of basal ornithischians. J Syst Palaeontol. 16:1159-1187.

He X-L, Cai K-J. 1984. The Middle Jurassic Dinosaurian Fauna from Dashanpu, Zigong, Sichuan. In: The ornithopod dinosaurs. Vol. I. Downs W, translator; Sichuan Scientific and Technological Publishing House, Chengdu; pp. 71.

Herne MC, Nair JP, Evans AR, Tait AM. 2019. New small-bodied ornithopods (Dinosauria, Neornithischia) from the Early Cretaceous Wonthaggi Formation (Strzelecki Group) of the Australian-Antarctic rift system, with revision of Qantassaurus intrepidus. J Paleontol. 93:543-584.

Herne MC, Tait AM, Weisbecker V, Hall M, Nair JP, Cleeland M, Salisbury SW. 2018. A new small-bodied ornithopod (Dinosauria, Ornithischia) from a deep, high-energy Early Cretaceous river of the Australian-Antarctic rift system. PeerJ. 5:e4113.

Horner J, Weishampel DB. 1988. A comparative embryological study of two ornithischian dinosaurs. Nature. 332:256-257.

Horner JN, Weishampel DB, Forster CA. 2004. Hadrosauridae. In: Weishampel DB, Dodson P, Osmolska H, editors. The dinosauria. 2nd ed. Berkeley: University of California Press; p. 438-463.

Hou L. 1977. A primitive pachycephalosaurid from the Cretaceous of Anhui, China, Wannanosaurus yansiensis gen. et sp. nov. Vert PalAs. 15:198-202.

Huh M, Lee D, Kim J, Lim J, Godefroit P. 2010. A new basal ornithopod dinosaur from the Upper Cretaceous of South Korea. Neues Jahrb Geol Palaeontol Abh. 259:1-24.

Janensch W. 1955. Der Ornithopod Dysalotosaurus der Tendaguruschichten [The ornithopod Dysalotosaurus from the Tendaguru]. Palaeontographica. Suppl. 7:105-176. German.

Langer MC, Benton MJ. 2006. Early dinosaurs: a phylogenetic study. J Syst Palaeontol. 4:309-358.

Langer MC, Ezcurra MD, Rauhut OWM, Benton MJ, Knoll F, McPhee BW, Novas FE, Pol D, Brusatte SL. 2017. Untangling the dinosaur family tree. Nature. 551:E1-E5.

Langer MC, Ferigolo J. 2013. The late Triassic dinosauromorph Sacisaurus agudoensis (Caturrita Formation; Rio Grande do Sul, Brazil): anatomy and affinities. Geol Soc London Spec Publ. 379:353-392.

Madzia D, Boyd CA, Mazuch M. 2018. A basal ornithopod dinosaur from the Cenomanian of the Czech Republic. J Syst Palaeontol. 16:967-979.

Madzia D, Jagt JWM, Mulder EWA. 2020. Osteology, phylogenetic affinities and taxonomic status of the enigmatic Late Maastrichtian ornithopod taxon Orthomerus dolloi (Dinosauria, Ornithischia). Cretac Res. 108. doi:10.1016/ j.cretres.2019.104334.

Makovicky PJ, Kilbourne BM, Sadleir RW, Norell MA. 2011. A new basal ornithopod (Dinosauria, Ornithischia) from the Late Cretaceous of Mongolia. J Vertebr Paleontol. 31:626-640.

Maryanska T, Osmolska H. 1974. Pachycephalosauria, a new suborder of ornithischian dinosaurs. Palaeontol Polonica. 30:45-102.

Maryanska T, Osmolska H. 1985. On ornithischian phylogeny. Palaeontol Polonica. 30:137-150.

Mateus O, Antunes MT. 2001. Draconyx loureiroi, a new camptosauridae (Dinosauria, Ornithopoda) from the Late Jurassic of Lourinha, Portugal. Ann Paléontol. 87:61-73.
Ösi A, Prondvai E, Butler R, Weishampel DB. 2012. Phylogeny, histology and inferred body size evolution in a New Rhabdodontid Dinosaur from the Late Cretaceous of Hungary. PLoS ONE. 7:e44318.

Mcdonald AT, Kirkland JI, Deblieux DD, Madsen SK, Cavin J, Milner ARC, Panzarin L. 2010. New basal iguanodonts from the cedar mountain formation of Utah and the evolution of thumb-spiked dinosaurs. PLoS ONE. 5: e14075.

Norman DB. 1980. On the ornithischian dinosaur Iguanodon bernissartensis from the Lower Cretaceous of Bernissart (Belgium). Mém l'Inst R Sci Nat Belg. 178:1-105.

Norman DB. 2004. Basal iguanodontia. In: Weishampel DB, Dodson P, Osmolska H, editors. The Dinosauria. 2nd ed. Berkeley: University of California Press; p. 413-437.

Norman DB, Sues H-D, Witmer LM, Coria RA. 2004. Basal ornithopoda. In: Weishampel DB, Dodson P, Osmolska H, editors. The dinosauria. 2nd ed. Berkeley: University of California Press; p. 393-437.

Norman DB, Crompton AW, Butler RJ, Porro LB, Charig AJ. 2011. The Lower Jurassic ornithischian dinosaur Heterodontosaurus tucki Crompton and Charig, 1962: cranial anatomy, functional morphology, taxonomy, and relationships. Zool J Linn Soc. 163:182-276.

Novas FE, Salgado L, Suárez M, Agnolín FL, Ezcurra MD, Chimento NR, De la Cruz R, Isasi MP, Vargas AO, Rubilar-Rogers D. 2015. An enigmatic plant-eating theropod from the Late Jurassic period of Chile. Nature. 522:331-334.

Osborn HF. 1924. Psittacosaurus and Protiguanodon: two lower Cretaceous iguanodonts from Mongolia. Am Mus Novit. 127:1-16.

Owen R. 1858. Monograph on the fossil Reptilia of the Wealden and Purbeck Formations. Part V. Lacertilia. Monogr Palaeontogr Soc. 12:31-39.

Padian K. 2013. The problem of dinosaur origins: integrating three approaches to the rise of Dinosauria. Earth Environ Sci Trans R Soc Edinburgh. 103:423-442.

Parks WA. 1926. Thescelosaurus warreni, a new species of orthopodous dinosaur from the Edmonton Formation of Alberta. Univ Tor Stud Geol Ser. 21:1-42.

Peng G. 1992. Jurassic ornithopod Agilisaurus louderbacki (Ornithopoda: Fabrosauridae) from Zigong, Sichuan, China. Vert PalAs. 30:39-53.

Perle A, Maryanska T, Osmolska H. 1982. Goyocephale lattimorei gen. et sp. n., a new flat-headed pachycephalosaur (Ornithischia, Dinosauria) from the Upper Cretaceous of Mongolia. Acta Palaeontol Pol. 27:8-132.

Pol D, Rauhut OWM, Becerra M. 2011. A Middle Jurassic heterodontosaurid dinosaur from Patagonia and the evolution of heterodontosaurids. Naturwissenschaften. 98:369-379.

Porro LB, Witmer LM, Barrett PM. 2015. Digital preparation and osteology of the skull of Lesothosaurus diagnosticus (Ornithischia: Dinosauria). PeerJ. 3:e1494.

Rotatori FM, Moreno-Azanza M, Mateus O. 2020. New information on ornithopod dinosaurs from the Late Jurassic of Portugal. Acta Palaeontol Pol. 65. doi:10.4202/app.00661.2019.

Rozadilla S, Agnolin FL, Novas FE. 2019. Osteology of the Patagonian ornithopod Talenkauen santacrucensis (Dinosauria, Ornithischia). J Syst Paleontol. 17:1-47.

Rozadilla S, Agnolin FL, Novas FE, Aranciaga Rolando AM, Matias JM, Lirio JM, Isasi MP. 2016. A new ornithopod (Dinosauria, Ornithischia) from the Upper Cretaceous of Antarctica and its palaeobiogeographical implications. Cretac Res. 57:311-324.

Rozadilla S, Cruzado-Caballero P, Calvo JO. 2020. Osteology of Ornithopod Macrogryphosaurus gondwanicus (Dinosauria, Ornithischia) from the Upper Cretaceous of Patagonia, Argentina. Cretac Res. doi:10.1016/j. cretres.2019.104311.

Ruiz-Omeñaca JI, Pereda Suberbiola X, Galton PM. 2007. Callovosaurus leedsi, the earliest dryosaurid dinosaur (Ornithischia: Euornithopoda) from the Middle Jurassic of England. In: Carpenter K, editor. Horns and Beaks: ceratopsian and ornithopod dinosaurs. Indiana University Press, Bloomington; p. 3-16.

Ruiz-Omeñaca JI, Canudo JI, Cuenca-Bescós G, Cruzado-Caballero P, Gasca JM, Moreno-Azanza M. 2012. A new basal ornithopod dinosaur from the Barremian of Galve, Spain. Comptes Rendus Palevol. 11(6):435.

Salgado L, Canudo JI, Garrido AC, Moreno-Azanza M, Martinez LCA Coria RA, Gasca JM. 2017. A new primitive neornithischian dinosaur from the Jurassic of Patagonia with gut contents. Sci Rep. 7:42778.

Salgado L, Coria RA, Heredia SE. 1997. New materials of Gasparinisaura cincosaltensis (Ornithischia, Ornithopoda) from the Upper Cretaceous of Argentina. J Paleontol. 71:933-940.

Santa Luca AP. 1980. The postcranial skeleton of Heterodontosaurus tuck (Reptilia, Ornithischia) from the Stormberg of South Africa. Ann S Afr Mus. 79:159-211.

Scheetz RD 1999. Osteology of Orodromeus malelai and the phylogeny of basal ornithopod dinosaurs. Unpublished $\mathrm{PhD}$ thesis, Montana State University, Bozeman, 186 pp. 
Schmidt-Lebuhn A. 2016. TNT script for the Templeton Test. See. https://www. researchgate.net/publication/306055781, also available at: https://www.anbg. gov.au/cpbr/tools/templetontest.tnt [both accessed 2020 Mar 03].

Seeley HG. 1887. On the classification of the fossil animals commonly named Dinosauria. Proc R Soc London. 43:165-171.

Senter P. 2007. Analysis of forelimb function in basal ceratopsians. J Zool. 273:305-314.

Sereno PC. 1984. The phylogeny of the Ornithischia: a reappraisal. In: Reif W, Westphal F, editors. Third Symposium on Mesozoic Terrestrial Ecosystems, Short Papers. Attempto Verlag: Tübingen University Press; p. 219-226.

Sereno PC. 1986. Phylogeny of the bird-hipped dinosaurs (Order Ornithischia). Natl Geogr Res. 2:234-256.

Sereno PC. 1991. Lesothosaurus, 'Fabrosaurids,' and the early evolution of Ornithischia. Journal of Vertebrate Paleontology. 11:168-197. doi:10.1080/ 02724634.1991.10011386

Sereno PC. 1993. The pectoral girdle and forelimb of the basal theropod Herrerasaurus ischigualastensis. J Vertebr Paleontol. 13:425-450.

Sereno PC. 1998. A rationale for phylogenetic definitions with application to higher-level taxonomy of Dinosauria. Neues Jabrb Geol Paläontol Abh. 210:41-83.

Sereno PC. 2000. The fossil record, systematics and evolution of pachycephalosaurs and ceratopsians from Asia. In: Benton MJ, Shishkin MA, Unwin DM, Kurochkin EN, editors. The age of dinosaurs in Russia and Mongolia. Cambridge: Cambridge University Press; p. 480-516.

Sereno PC. 2005. Stem Archosauria-TaxonSearch [updated version 1.0, 2005 November 7, accessed 2020 May 30]. http://taxonsearch.uchicago.edu/.

Sereno PC. 2010. Taxonomy, cranial morphology, and relationships of parrotbeaked dinosaurs (Ceratopsia: Psittacosaurus). In: Ryan MJ, ChinneryAllgeier BJ, Eberth DA, editors. New perspectives on horned dinosaurs: the Royal Tyrrell Museum Ceratopsian Symposium. Indiana University Press, Bloomington; p. 219-226.

Sereno PC. 2012. Taxonomy, morphology, masticatory function and phylogeny of heterodontosaurid dinosaurs. ZooKeys, 226:1-225.

Sereno PC, Novas FE. 1993. The skull and neck of the basal theropod Herrerasaurus ischigualastensis. J Vertebr Paleontol. 13:451-476.

Slowiak J, Tereshchenko V, Fostowicz-Frelik L. 2019. Appendicular skeleton of Protoceratops andrewsi (Dinosauria, Ornithischia); comparative morphology, ontogenetic changes, and the implications for non-ceratopsid ceratopsian locomotion. PeerJ. 7:e7324.

Snively E, Theodor JM. 2011. Common functional correlates of head-strike behavior in the Pachycephalosaur Stegoceras validum (Ornithischia, Dinosauria) and combative artiodactyls. PLoS ONE. 6:e21422.

Sues H-D. 1980. Anatomy and relationships of a new hypsilophodontid dinosaur from the Lower Cretaceous of North America. Palaeontogr Abt A, 169, 51-72.

Sues H-D, Norman DB. 1990. Hypsilophodontidae, Tenontosaurus and Dryosauridae. In: Weishampel DB, Dodson P, Osmolska H, editors. The dinosauria. 1st ed. Berkeley: University of California Press; p. 498-509.

Sues H-D, Galton PM. 1987. Anatomy and classification of the North American Pachycephalosauria (Dinosauria: Ornithischia). Palaeontogr Abt A. 198:1-40.
Tanoue K, You H-L, Dodson P. 2010. Mandibular anatomy in basal ceratopsia. In: Ryan MJ, Chinnery-Allgeier BJ, Eberth DA, editors. New perspectives on horned dinosaurs: the Royal Tyrrell Museum Ceratopsian Symposium. Bloomington: Indiana University Press; p. 234-250.

Templeton A. 1983. Phylogenetic inference from restriction endonuclease cleavage site maps with particular reference to the evolution of humans and the apes. Evolution. 37:221-244.

Tennant J 2013. Osteology of a near-complete skeleton of Tenontosaurus tilletti (Dinosauria: Ornithopoda) from the Cloverly Formation, Montana, USA [master's thesis]. University of Manchester, Manchester, $195 \mathrm{pp}$.

Thomas DA. 2015. The cranial anatomy of Tenontosaurus tilletti Ostrom, 1970 (Dinosauria, Ornithopoda). Palaeontol Electron. 18:1-99.

Vickaryous MK, Maryanska T, Weishampel DB. 2004. Ankylosauria. In: Weishampel DB, Dodson P, Osmolska H, editors. The dinosauria. 2nd ed. Berkeley: University of California Press; p. 363-392.

Weishampel DB, Heinrich RE. 1992. Systematics of hypsilophodontidae and basal Iguanodontia (Dinosauria: Ornithopoda). Hist Biol. 6:159-184.

Weishampel DB, Jianu C-M, Csiki Z, Norman DB. 2003. Osteology and phylogeny of Zalmoxes (n. g.), an unusual Euornithopod dinosaur from the latest Cretaceous of Romania. J Syst Palaeontol. 1:65.

Wiens JJ. 2005. Can incomplete taxa rescue phylogenetic analyses from long-branch attraction? Syst Biol. 54:731-742.

Winkler DA, Murry PA, Jacobs LL. 1997. A new species of Tenontosaurus (Dinosauria; Ornithopoda) from the Early Cretaceous of Texas. J Vertebr Paleontol. 17:330-348.

Winkler DA, Murry PA, Jacobs LL, Downs WR, Branch JR, Trudel P. 1988. The Proctor Lake Dinosaur locality, Lower Cretaceous of Texas. Hunteria. 2:1-8.

Xu X, Forster CA, Clark JM, Mo J. 2006. A basal ceratopsian with transitional features from the Late Jurassic of northwestern China. Proc R Soc London Ser B. 273:2135-2140.

Xu X, Makovicky PJ, Wang X, Norell MA, You H. 2002. A ceratopsian dinosaur from China and the early evolution of ceratopsia. Nature. 416:314-317.

You H-L, Dodson P. 2004. Basal ceratopsia. In: Weishampel DB, Dodson P, Osmolska H, editors. The dinosauria. 2nd ed. Berkeley: University of California Press; p. 478-493.

You H-L, Dodson P. 2003. Redescription of neoceratopsian dinosaur Archaeoceratops and early evolution of Neoceratopsia. Acta Palaeontol Pol. 48:261-272.

You H-L, Tanoue K, Dodson P. 2008. New data on cranial anatomy of the ceratopsian dinosaur Psittacosaurus major. Acta Palaeontol Pol. 53:183-196.

Zhao X, Cheng Z, Xu X. 1999. The earliest ceratopsian from the Tuchengzi Formation of Liaoning, China. J Vertebr Paleontol. 19:681-691.

Zheng W, Jin X, Shibata M, Azuma Y, Yu F. 2012. A new ornithischian dinosaur from the Cretaceous Liangtoutang Formation of Tiantai, Zhejiang Province, China. Cretac Res. 34:208-219.

Zheng X-T, You H-L, Xu X, Dong Z-M. 2009. An Early Cretaceous heterodontosaurid dinosaur with filamentous integumentary structures. Nature. 458:333-336. 